\title{
Time-Varying Market Leverage and the Market Risk Premium in New Zealand
}

by

Danyi Bao

\author{
A thesis \\ submitted to the Victoria University of Wellington \\ in fulfilment of the \\ requirements for the degree of \\ Master of Commerce and Administration \\ in Money and Finance \\ Victoria University of Wellington \\ 2008
}




\begin{abstract}
This paper applies the Ibbotson and Sinquefield (1976) method and the Lally (2002) method to New Zealand data over the period 1960-2005 in order to estimate the market risk premium (MRP) in two versions of the capital asset pricing model (CAPM). With respect to the standard CAPM, the resulting Ibbotson estimate of the MRP for New Zealand was $6.11 \%$. The resulting Lally estimate of the MRP ranged from 5.52\% (in 1970) to $18.40 \%$ (in 1990), with an average of $7.95 \%$, and was $6.40 \%$ for 2005 . With respect to the simplified Brennan-Lally CAPM, the resulting Ibbotson estimate of the MRP for New Zealand was $8.49 \%$. The resulting Lally estimate of the MRP ranged from $7.91 \%$ (in 1970) to $20.79 \%$ (in 1990), with an average of $10.33 \%$, and was $8.78 \%$ for 2005 . The Lally and the Ibbotson estimates of the MRP are similar in general. However, when market leverage is unusually high or low, they diverge significantly. In future, practitioners may need to choose between the estimates from the two methods when market leverage goes beyond the normal level.
\end{abstract}




\section{Acknowledgements}

I would like to thank my primary supervisor, Martin Lally, for providing me the opportunity to work on this topic, for sharing his expertise, and for his constructive guidance throughout this thesis. I would also like to thank my secondary supervisor, Lyndon Moore, for his many ideas and valuable comments. Sam Brodie and Stacey Campbell from New Zealand Stock Exchange are thanked for supplying data. I thank the School of Economics and Finance at Victoria University of Wellington for financial support. Finally, I wish to express thanks to my family for their support all the time, and special thanks to my dear friend, Jackki Yim, for her encouragement and good company. 


\section{Contents}

1 Introduction 4

2 Literature Review $\quad 7$

2.1 Two Forms of the CAPM . . . . . . . . . . . . 7

2.2 Approaches to Estimating the MRP . . . . . . . . . . . 8

2.2.1 Historical Averaging Approaches . . . . . . . . 8

2.2.2 Forward-Looking Approaches . . . . . . . . . . . . 12

2.2.3 Time-Varying Approaches . . . . . . . . . . . . 17

3 Method and Data $\quad 21$

3.1 The Ibbotson MRP Estimator . . . . . . . . . . . . . . . . 22

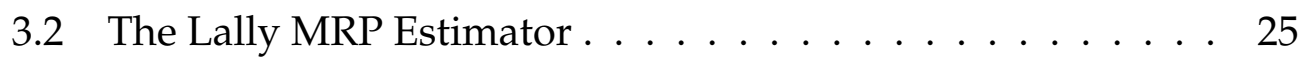

3.3 Data and Data Issues . . . . . . . . . . . . . . . . 27

3.3.1 The Market Return . . . . . . . . . . . . . . . . . 28

3.3.2 The Risk Free Rate . . . . . . . . . . . . . . . 28

3.3.3 Market Leverage . . . . . . . . . . . . . . . . . 29

3.3.4 Data Issues for Market Leverage . . . . . . . . . . . . 34

3.3.5 Corporate Bond Returns . . . . . . . . . . . . . . . 49

4 Results and Analysis $\quad 56$

4.1 Results for the Standard CAPM . . . . . . . . . . . . 56

4.2 Results for the Simplified Brennan-Lally

CAPM ........................... 58 
4.3 Intertemporal Variation in the Lally MRP . . . . . . . . . 61

4.4 Further Results . . . . . . . . . . . . . . . . . . . 63

5 Conclusion $\quad 65$

A Estimation of the Market Value of Debt 67

B Summary of Data $\quad 75$ 


\section{List of Tables}

2.1 Previous Estimates of the MRP in New Zealand . . . . . . . 20

3.1 Number of Companies in the Market Portfolio Proxy and the Equity Index . . . . . . . . . . . . . . . . . 32

3.2 Estimated Market Leverage and Cumulative Index Weights 33

3.3 Market Equity, Market Debt and Market Leverage . . . . . . 34

3.4 Equity Valuation Dates and Acceptable Balance Dates . . . . 36

3.5 Estimates of Market Leverage in 2005 with and without Adjustments . . . . . . . . . . . . . . 40

3.6 Consolidated Balance Sheet of Fletcher Challenge Ordinary Division in December 1995 . . . . . . . . . . . . . . . . 41

3.7 The Aggregate Book Value of Minority Interests to the Aggregate Book Value of Total Shareholders' Funds from 1960 to $2005 \ldots \ldots \ldots$. . . . . . . . . . . . . . . . . . . . 42

3.8 Estimated Market Leverage With and Without Consideration of Minority Interests . . . . . . . . . . . . . . . . 44

3.9 The Aggregate Book Value of Convertible Notes Held by Companies in the Market Portfolio and the Aggregate Debt Value of these Companies . . . . . . . . . . . . . 45

3.10 The Aggregate Market Value of Convertible Notes Included in the Equity Index and the Aggregate Market Capitalisation of the Equity Index . . . . . . . . . . . . . 45 
4.1 Estimates of the Ibbotson MRP and the Lally MRP in the Standard CAPM . . . . . . . . . . . . . . . . 57

4.2 Estimates of the Ibbotson MRP and the Lally MRP in the Simplified Brennan-Lally Version of the CAPM . . . . . . . . 60

4.3 Estimates of the Ibbotson and the Lally MRP in the standard CAPM by Using Data over the Periods 1960-1985, 19601990, 1960-2000, and 1960-2005 . . . . . . . . . . . . 64

A.1 Comparison between the Book Value and the Market Value of Debt with Fixed Interest Rates in the 1990 Market Portfolio 73

A.2 The Book and Market Values of Aggregate Debt, Market Leverage, and MRP Estimates in the 1990 Market Portfolio . 74

B.1 Total Data Sets for this Paper . . . . . . . . . . . 75 


\section{List of Figures}

3.1 Method One with Proper Time Adjustments . . . . . . . . . 37

3.2 Method Two with Proper Time Adjustments . . . . . . . . . 38

3.3 US MRP Estimates from Using $R_{d}$ and from Using $R_{r}$ as a Proxy for $R_{d} \ldots \ldots \ldots \ldots \ldots \ldots \ldots \ldots$

3.4 The Difference between US Corporate Bond Returns and US Government Bond Returns from 1952 to 1997 . . . . . . . . . 53

3.5 The Difference between NZX Corporate Bond Returns and NZ Government Bond Returns from 1994 to 2005 . . . . . . . 54

4.1 Estimates of the Ibbotson MRP and the Lally MRP in the Standard CAPM . . . . . . . . . . . . . . 58

4.2 Estimates of the Ibbotson MRP and the Lally MRP in the Simplified Brennan-Lally Version of the CAPM . . . . . . . . 61

4.3 Ratio of Market Debt to Market Capitalisation . . . . . . . . 61

4.4 Market Capitalisation and Market Debt . . . . . . . . . . . 62

A.1 Fourth-Quarter-Ended Inflation Rates from 1960 to 2005 . . 68

A.2 Monthly Average Yield on One-Year Secondary Market Government Bonds over the Period 1987 to 2005 . . . . . . . . . . 69 


\section{Chapter 1}

\section{Introduction}

Equity investment is very risky, in the sense that equity returns are highly volatile and equity holders do not have priority over a company's assets in the event of bankrupty. The reward for bearing this risk from holding equities, rather than the risk free asset, is called the market risk premium (MRP). In the standard Capital Asset Pricing Model (Sharpe, 1964; Lintner, 1965; Mossin, 1966), it is defined as the expected return on the market portfolio in excess of the risk free rate of return, and is a forward-looking concept.

The MRP has attracted considerable attention in the field of modern corporate finance. It is a key factor in determining the cost of equity in any version of the Capital Asset Pricing Model (CAPM). A good estimate of the MRP enables better investment decision making, more efficient portfolio management, and more reasonable setting of target returns for companies or government organisations.

The MRP cannot be observed and has to be estimated. Various approaches to estimating the MRP have been developed, including historical averaging approaches, forward-looking approaches, and time-varying approaches. The two principal historical averaging approaches are the Ibbotson and Sinquefield (1976) method and the Siegel (1992) method. While the former estimates the MRP by averaging the market return in 
excess of the risk free rate over a long period, the latter averages the real market return and then deducts the expected real risk free rate. Forwardlooking approaches are different from historical averaging approaches in that they estimate the MRP from future expectations rather than from historical data. Two principal such approaches are the dividend discount model (DDM) and the residual income model (RIM). The DDM treats the expected market return as the discount rate and values the market portfolio by discounting future expected dividends. The RIM is derived from the DDM. It values the equity as the sum of its current book value and the present value of its expected future abnormal earnings (beyond a fair rate of return on equity). Time-varying approaches associate the MRP with a market factor that varies over time. Merton (1980) introduces the method by modelling the MRP as proportional to market variance (or standard deviation). Although previous studies have shown evidence of a positive relationship between the MRP and market variance, the form of the relationship remains unclear.

Lally (2002) develops a time-varying MRP estimator, which overcomes some problems with the Merton estimator. The Lally method is based on the work of Modigliani and Miller $(1958,1963)$, whose proposition II specifies the relationship between a company's cost of equity and its leverage. When the market portfolio is proxied by an equity portfolio (as usual), market leverage (the aggregate debt of companies comprising the market portfolio divided by their aggregate value) should therefore affect the expected return on the "market" portfolio and hence the MRP. The variation over time in market leverage can be substantial. For example, the 1987 stock market crash caused large reductions in equity values, and consequently raised market leverage. Accordingly, the MRP should have risen. Therefore, the MRP should be sensitive to market leverage if the market portfolio contains only equities.

The motivation for this paper is to apply Lally's leverage-sensitive MRP estimator to New Zealand data and to examine how the estimated MRP 
varies with market leverage over time. As the Lally MRP estimator has not yet been applied to New Zealand data, the results may be of interest to both academics and practitioners.

Chapter 2 reviews the current literature on three major approaches to estimating the MRP: historical averaging approaches, forward-looking approaches, and time-varying approaches. Their benefits and limitations are discussed. Chapter 3 describes the application of the Lally MRP estimator and the Ibbotson MRP estimator to New Zealand data over the period 1960-2005. It describes the methods involved in estimating the MRPs in both the standard CAPM and the simplified Brennan-Lally CAPM (Cliffe and Marsden, 1992; Lally, 1992). It also discusses the collection processes for the five required data sets under the standard CAPM: market returns, risk free rates of return, market debt values, market equity values, and the returns on corporate bonds. Chapter 4 provides the results from applying the two MRP estimators. With respect to the standard CAPM, the Lally MRP estimate ranged from $5.52 \%$ to $18.4 \%$ over the period $1960-2005$, with an average of $7.95 \%$ and a value of $6.40 \%$ for 2005 , whereas the Ibbotson MRP estimate was $6.11 \%$. With respect to the simplified Brennan-Lally CAPM, the Lally estimate ranged from $7.91 \%$ to $20.79 \%$, with an average of $10.33 \%$ and a value of $8.78 \%$ for 2005 , whereas the Ibbotson estimate was $8.49 \%$. Chapter 5 concludes. 


\section{Chapter 2}

\section{Literature Review}

The market risk premium (MRP) is very important in determining the cost of equity. However, it is not observable and has to be estimated. Over the course of many studies, various approaches to estimating the MRP have been suggested. This chapter first introduces two forms of the Capital Asset Pricing Model (CAPM), for which various approaches to estimating their MRPs have been adopted using New Zealand data. It then provides a brief discussion on three major types of approaches to estimating the MRP: historical averaging approaches, forward-looking approaches, and time-varying approaches. Previous applications of these approaches to New Zealand data are also summarised.

\subsection{Two Forms of the CAPM}

There are two forms of the CAPM that we will consider when estimating the MRP for New Zealand, consistent with their widespread use in New Zealand. One is the standard version of the CAPM, and the other is the Brennan-Lally version of the CAPM.

In the standard CAPM (Sharpe, 1964; Lintner, 1965; Mossin, 1966), the MRP is defined as $E\left(R_{m}\right)-R_{f}$, where $E\left(R_{m}\right)$ is the expected rate of return on the market portfolio and $R_{f}$ is the risk free rate of return. The standard 
CAPM has been applied worldwide for many years. However, for New Zealand purposes, this version of the CAPM neglects the local taxation features, such as the dividend imputation system.

The Brennan-Lally version of the CAPM (Cliffe and Marsden, 1992; Lally, 1992) is an extension of the work of Brennan (1970). It defines the MRP as $E\left(R_{m}\right)-D_{m} T_{m}-R_{f}\left(1-T_{I}\right)$, where $D_{m}$ is the cash dividend yield on the market portfolio, and $T_{m}$ and $T_{I}$ are tax parameters. A simplified version of it assumes that capital gains taxes are zero for all investors, and that imputation credits are attached at the maximum possible rate. Currently, the values for $T_{m}$ and $T_{I}$ are generally agreed to be zero and 0.33 , respectively, in the simplified version.

The Brennan-Lally CAPM takes into account differential personal taxes on interest income, capital gains, and dividends. It has been favoured by many New Zealand organisations ${ }^{1}$ in recent decades. In practice, it is common for the MRP to be estimated under both the standard CAPM and the Brennan-Lally CAPM.

\subsection{Approaches to Estimating the MRP}

A significant body of literature discusses a variety of approaches to estimating the MRP. Three major types are historical averaging approaches, forward-looking approaches, and time-varying approaches. The following section summarises this literature.

\subsubsection{Historical Averaging Approaches}

The two principal historical averaging approaches are the Ibbotson and Sinquefield (1976) method and the Siegel (1992) method. The former method

\footnotetext{
${ }^{1}$ For example, The Treasury, the Commerce Commission, Transpower, Telecom NZ, First New Zealand Capital, Goldman Sachs JBWere Ltd, PricewaterhouseCoopers, and Forsyth Barr.
} 
has been applied to New Zealand data by Chay et al. $(1993,1995)$, PricewaterhouseCoopers (2002), and Lally and Marsden (2004b), and the latter method has been applied by Lally and Marsden (2004a) and Marsden (2005).

\section{Ibbotson Method}

The Ibbotson method, introduced by Ibbotson and Sinquefield (1976), is the simplest and most widely applied method for estimating the MRP within the standard CAPM. It estimates the MRP by averaging the historical annual excess return (the market return in excess of the risk free rate of return) over a long term. The Ibbotson method is based on the presumption that the true value of the MRP does not change over time. Hence, averaging past data provides an unbiased estimate for the future.

However, changes in various factors call into question the presumption of a constant MRP. Mayfield (2004) indicates that the Ibbotson method can lead to seriously biased MRP estimates in the presence of a structural shift in market volatility. The scaling back of strict government intervention in the New Zealand economy in 1984, the stock market crash in 1987, and the introduction of the dividend imputation system in New Zealand in 1988 could have had an impact on the true value of the MRP. McCulloch and Leonova (2005) list a series of potential changes (e.g. lower costs for investment diversification, reduction in transaction costs, lower risk aversion of investors, etc.) to the New Zealand capital market, which may alter the MRP in the future. All these lead to a major issue with the Ibbotson method: the choice of the time span.

The choice of time span involves a tradeoff between data relevance and statistical precision. Using historical data over a long period raises the possibility of the older data being irrelevant to the estimation of the MRP for the future, when the true MRP shifts over time. However, using a short period can also be problematic. Stock returns are so volatile that averaging over a short period will lead to large statistical errors (i.e. a large 
confidence interval for the estimated MRP). Pastor and Stambaugh (2001) demonstrate that using a long sample period improves the MRP estimate even if structural breaks exist in historical equity returns. Siegel (1992) implies that estimation errors can be substantial even using a very long time series of data (US data over nearly 200 years). Hence, although the optimal time period is unclear, a long period would seem to be preferable.

Another major concern with the Ibbotson method relates to the form of averaging. Lally and Marsden (2004b) show that using the arithmetic average of the historical annual excess return generates an MRP estimate of $5.5 \%$, while the geometric average generates an estimate of $2.9 \%$. Hence, the form of averaging can significantly affect the estimate of the MRP.

Consideration must be given not only to the accuracy of this average but also to the use to which this average is put. Blume (1974) shows that the compounded arithmetic mean $\left(A^{n}\right)$ is biased upwards and the compounded geometric mean $\left(G^{n}\right)$ is biased downwards. Hence, for compounding purposes, he proposes a new estimator - the weighted average of the compounded geometric and arithmetic means. This would provide a value somewhere between them. Blume's assessment of biases, by using different forms of averaging, assumes independently distributed equity returns. Where the distribution of equity returns is dependent, Blume suggests that the arithmetic average still introduces the least bias. However, Indro and Lee (1997) show that, with serial correlation in equity returns, Blume's weighted estimator provides the least biased estimate. While both Blume (1974) and Indro and Lee (1997) use the estimator for compounding, Cooper (1996) uses it for discounting, and finds that the arithmetic mean is less biased than the geometric mean as a discount rate. Since the MRP is popularly used to value projects, the accuracy of discounting is more important than compounding. Hence, Cooper's analysis, which is concerned with discounting, is more relevant, and it is therefore reasonable to favour the arithmetic average.

Other issues that arise from use of the Ibbotson method relate to the use 
of long-term or short-term government bond yields as a proxy for the risk free rate (Booth, 1999), the use of an equity portfolio as a proxy for the market portfolio (Roll, 1977; Kandel and Stambaugh, 1987; Shanken, 1987; Roll and Ross, 1994), survivorship bias (Brown et al., 1995; Jorion and Goetzmann, 1999; Dimson et al., 2000), and the effects of unexpected inflation on real market returns and bond returns (Siegel, 1992, 1999). Nevertheless, the Ibbotson method still attracts considerable attention, as it is easily applied, the required data sets are usually obtainable, and the results are relatively stable over time.

\section{Siegel Method}

Siegel $(1992,1999)$ argues that the Ibbotson MRP estimate is biased upwards due to unexpected inflation in the period 1926-90, especially 196585. As companies can, in general, raise their output prices to maintain their real returns but bond payoffs are fixed, unexpected inflation lowers the real return on government bonds but has almost no effect on real (equity) market returns. Put another way, unexpected inflation does not change nominal bond returns but it raises equity returns. This results in the Ibbotson MRP estimate being biased upwards in the presence of unexpectedly high inflation.

In view of this, Siegel (1992) uses historical averaging of the real market return, and then deducts an estimate of the expected real risk free return (rather than the historical average of the real risk free return), to estimate the MRP. Siegel's MRP estimate is much smaller than the Ibbotson estimate. Over the sample period 1802-1990, it is about half of the corresponding Ibbotson estimate for the US. Lally and Marsden $(2004 a, b)$ show a much smaller difference (within 1.7\%) between the Siegel and the Ibbotson estimates in New Zealand. Hence, the Ibbotson MRP estimate for New Zealand has not been affected by unexpected inflation as much as for the US. 


\subsubsection{Forward-Looking Approaches}

Unlike historical averaging approaches, which estimate the MRP from historical data, forward-looking approaches estimate the MRP from expectations of the future. Hence, forward-looking approaches avoid most limitations of the historical averaging approach. They are consistent with the MRP being a forward-looking concept. Two principal forward-looking approaches are the dividend discount model (DDM) and the residual income model (RIM). Lally (2001) has applied the DDM to New Zealand data. To my knowledge, the RIM has not yet been applied in New Zealand.

\section{Dividend Discount Model}

The DDM values the market portfolio (which is usually proxied by an equity portfolio) through discounting future expected dividends by the expected market return:

$$
P_{m}=\frac{D I V_{m}\left(1+g_{1}\right)}{1+E\left(R_{m}\right)}+\frac{D I V_{m}\left(1+g_{1}\right)\left(1+g_{2}\right)}{\left[1+E\left(R_{m}\right)\right]^{2}}+\cdots
$$

where

$$
\begin{aligned}
D I V_{m} & =\text { current market dividends } \\
g_{1}, g_{2}, \cdots & =\text { expected dividend growth rates for year } 1,2, \ldots \\
E\left(R_{m}\right) & =\text { expected market return } \\
P_{m} & =\text { current value of the market portfolio. }
\end{aligned}
$$

Dividing both sides by $P_{m}$ gives:

$$
1=\frac{D Y_{m}\left(1+g_{1}\right)}{1+E\left(R_{m}\right)}+\frac{D Y_{m}\left(1+g_{1}\right)\left(1+g_{2}\right)}{\left[1+E\left(R_{m}\right)\right]^{2}}+\cdots
$$

where $D Y_{m}$ represents the current market dividend yield and is observable. By inputting the value for $D Y_{m}$ and the estimates for the expected dividend growth rate $\left(g_{1}, g_{2}, \cdots\right)$, the expected market return $E\left(R_{m}\right)$ can be estimated through equation 2.2. Given the risk free return $\left(R_{f}\right)$, the MRP can then be estimated through $M R P=E\left(R_{m}\right)-R_{f}$ in the standard 
CAPM. Alternatively, the DDM can be applied at the individual company level first. The resulting estimates of each company's expected equity return are then value weighted, to yield an estimate for the expected market return and hence the estimate of the MRP.

Different assumptions have been made about the expected dividend growth rates, resulting in three versions of the DDM: the one-stage version, the two-stage version, and the three-stage version.

The one-stage version of the DDM refers to the Gordon (1962) dividend growth model, where the expected dividend growth rate is assumed to be constant in perpetuity. Hence, equation 2.2 can be simplified to:

$$
1=\frac{D Y_{m}(1+g)}{E\left(R_{m}\right)-g}
$$

where $g=g_{1}=g_{2}=\cdots$.Consequently,

$$
E\left(R_{m}\right)=D Y_{m}(1+g)+g .
$$

Harris and Marston (1992) use the five-year earnings growth rate forecast by equity analysts as a proxy for $g$, and generate an average of the MRP estimates for the US over the period 1982-91 at 6.47\%. However, Claus and Thomas (2001) argue that the Gordon model produces an MRP estimate that is biased upwards; since the five-year earnings growth rate substantially exceeds the expected growth rate in GDP, it is too large to be a reasonable proxy for the expected dividend growth in perpetuity.

Both the two-stage and the three-stage versions of the DDM separate the expected dividend growth rate into a short-run part and a long-run part. While the two-stage version of the DDM requires the short-run rate to converge to the long-run rate immediately, the three-stage version contains a transition period. Damodaran (1999) applies the two-stage version of the DDM to 1997 US data (with a short-run earnings growth rate estimated at around $10 \%$ over the first five years and a long-run rate estimated at $5 \%$ thereafter), yielding an MRP estimate of 2.95\%. Cornell (1999) 
applies the three-stage version of the DDM. He uses the five-year forecast earnings growth rate as a proxy for the short-run expected dividend growth rate over the first five years, and the long-run expected nominal growth in GDP as a proxy for the long-run expected dividend growth rate from the twentieth year in perpetuity. The period between the fifth year and the twentieth year is the transition period, which involves a linear convergence from the short-run estimate to the long-run estimate. Cornell's MRP estimate is $4.5 \%$, which is about $3.5 \%$ less than the corresponding Ibbotson MRP estimate. As the estimate of the long-run expected dividend growth rate is much smaller than the estimate of the short-run expected dividend growth rate, the resulting MRP estimates from the two-stage and the three-stage versions of the DDM are lower than the one-stage version.

Nevertheless, Bernstein and Arnott (2003) demonstrate that using the long-run nominal growth rate in GDP as a proxy for the long-run expected dividend growth rate is too strong. The current price of equity is the present value of dividends to existing shareholders in existing companies, and $g$ should then be the long-run expected growth rate in these dividends. However, the long-run growth rate in GDP is greater than the long-run expected dividend growth rate to existing shareholders in existing companies, because existing companies will issue new equity capital to new shareholders and new companies will enter the market. Bernstein and Arnott (2003) suggest a 2\% deduction from the long-run expected growth rate in GDP to account for these factors. The two methods they use to generate this $2 \%$ adjustment are to compare the real dividend growth rate (to existing shareholders in existing companies) with real GDP growth for many countries from 1900 to 2000, and also to compare the market capitalisation growth rate with the growth rate in a value weighted price index for equity. However, the first of these methodologies is exposed to the possibility of the dividend payout rate falling over time. The second is exposed to foreign listings and listing of US companies that already exist. 


\section{Residual Income Model}

The RIM values equity as the sum of the current book value of the equity and the present value of the expected future abnormal earnings. The RIM is derived from the DDM using the so-called "clean surplus" relation:

$$
D I V_{t}=\Pi_{t}-\left(B_{t}-B_{t-1}\right)
$$

where

$$
\begin{aligned}
D I V_{t} & =\text { dividends in year } t \\
\Pi_{t} & =\text { earnings for year } t \\
B_{t} & =\text { book value of equity at the end of year } t .
\end{aligned}
$$

The RIM can be expressed as:

$$
P_{m}=B_{0}+\frac{E\left(a e_{1}\right)}{1+E\left(R_{m}\right)}+\frac{E\left(a e_{2}\right)}{\left[1+E\left(R_{m}\right)\right]^{2}}+\cdots
$$

where

$$
\begin{aligned}
B_{0} & =\text { current book value of equities } \\
a e_{t} & =\text { abnormal earnings for year } t \\
& =\Pi_{t}-E\left(R_{m}\right) B_{t-1}
\end{aligned}
$$

The RIM requires the estimation of expected abnormal earnings. Claus and Thomas (2001) apply a two-stage version of the RIM. They use earnings forecasts for the first five years and assume that expected abnormal earnings grow at a constant rate equal to the expected inflation rate thereafter. The resulting MRP estimates over the period 1985-98 range from $2.5 \%$ to $4.0 \%$, with a mean of $3.4 \%$ (about $3 \%$ lower than the estimates under the Ibbotson method). Due to the evidence of a systematic upward bias in earnings forecasts, Claus and Thomas suggest a further downward adjustment to their results.

To summarise, the one-stage version of the DDM suffers from the problems of determining a reasonable estimate for the expected dividend growth rate in perpetuity and (in the event of using analysts' five-year earnings 
per share forecasts as a proxy for the expected dividend growth rate) considerable variation in the estimated MRP over time. The multistage versions of the DDM and the RIM are similar in terms of producing relatively low and stable MRP estimates over time. One significant benefit of using the RIM is that earnings forecasts and current book values of equity are available from analysts and accounting statements. The DDM, however, has to use a proxy for the expected dividend growth rate, which is subject to estimation errors. Schroeder (2005) makes a comprehensive comparison of the DDM and the RIM, and finds that, although the MRP estimates from a two-stage RIM and a three-stage DDM differ the least, the DDM is superior due to the fact that its individual firm risk premia are better explained by individual firm risk parameters, such as beta.

Overall, although forward-looking approaches avoid the data problems of historical averaging approaches, they raise some new issues. First, the MRP estimates are sensitive to assumptions made about underlying parameters, such as the long-run expected dividend growth rate under the DDM and the long-run expected growth rate of abnormal earnings under the RIM. Second, analysts' five-year earnings forecasts and their growth rate, which are commonly used in the DDM and the RIM, are subject to a systematic optimism bias. ${ }^{2}$ Claus and Thomas (2001) indicate that it is hard to determine the magnitude of this bias. Third, the MRP estimates are sensitive to the current price of the market portfolio (or equities). This implies that, if the observed price deviates from the "fundamental value", the resulting MRP estimate will be wrong. Hence, attention needs to be paid to these issues when applying forward-looking approaches.

\footnotetext{
${ }^{2}$ Equity analysts can diverge from the market participants who price the equity. There is a presumption that market prices of equity are correctly set.
} 


\subsubsection{Time-Varying Approaches}

Many studies support the existence of a time-varying MRP (Merton, 1980; Conrad and Kaul, 1988; Fama and French, 1989; Ferson and Harvey, 1991; Evans, 1994). Time-varying approaches associate the MRP with some timevarying market factors. Two such approaches are the Merton (1980) method and the Lally (2002) method.

\section{Merton Method}

Merton (1980) investigates the relationship between the MRP and market risk. He builds three models of the relationship. The first assumes that the MRP is proportional to market variance, the second assumes that the MRP is proportional to market standard deviation, and the third assumes that the MRP is constant. As the CAPM implies that the MRP is proportional to market variance, the first model is preferred. Merton's estimation involves two stages. The first stage estimates the coefficients for the model. The second stage estimates market variance (or standard deviation).

The Merton method faces a tradeoff in determining the time span over which market variance (or standard deviation) is estimated. If the time span is long, the estimated variance (or standard deviation) does not fully reflect the variation of volatility over time, which is inconsistent with the presumption of a time-varying MRP. If the time span is short, the estimated variance (or standard deviation) is subject to the potential for large estimation error, resulting in unreliable MRP estimates. Volatility over different time spans, such as a day, a month, or a year, can be very different. Hence, it is difficult to determine an optimal time span, over which the estimated variance (and standard deviation) correctly and accurately reflects the variation of market risk over time.

Although Merton (1980) concludes that there is a positive relationship between the MRP and market variance, some empirical studies show contrary results. French et al. (1987), Baillie and DeGennaro (1990), and Boudo- 
ukh et al. (1997) suggest that there is an insignificant relationship between the MRP and market variance. However, Harvey (1989) and Turner et al. (1989) conclude that there is a significant positive relationship, whereas Campbell (1987) and Glosten et al. (1993) find a significant negative relationship. Scruggs (1998) summarises these previous controversial findings and explains that they are due to the use of single-factor models. Some single-factor models neglect the effect of a government bond return factor, leading to finding an insignificant relationship. Some single-factor models include the nominal risk free rate in the estimation for market variance, leading to finding a negative relationship. Scruggs (1998) concludes that there is a significant positive relationship between the MRP and market variance, by using a two-factor model. The more recent study of Goyal and Santa-Clara (2003), however, finds an insignificant relationship between market variance and the MRP. They explain that, because their estimation does not take into account other state variables, the result is compatible with that of Scruggs (1998).

Even where one believes that there is a positive relationship between the MRP and market variance, the form of the relationship remains unresolved. Harvey (1989) shows that this relationship varies over time. It is also possible that, due to the difficulty in estimating market variance, it is hard to quantify the relationship between the MRP and market variance.

The Merton method was first applied by Credit Suisse First Boston (1998) in New Zealand for both the standard and Brennan-Lally versions of the CAPM. Lally (2000) and Boyle (2005) have also estimated the MRP in New Zealand by using the Merton method.

\section{Lally Method}

Lally (2002) develops a time-varying MRP estimator, which associates the MRP with market leverage. Leverage is a particular source of risk. A higher level of leverage implies greater variability in shareholders' returns. This is because bondholders have higher priority over the com- 
pany's cash flows than shareholders, as well as over the company's assets in the event of bankruptcy. Modigliani and Miller $(1958,1963)$ proposition II develops the relationship between a company's cost of equity and its leverage. When the market portfolio is proxied by an equity portfolio (as usual), market leverage should therefore affect the expected return on the "market" portfolio and hence the MRP. Since this relationship is theoretically developed, it avoids many estimation problems of the Merton estimator, which is empirically developed.

Lally (2002) applied his method to US data over the period 1952-97 and shows that the resulting estimates of the MRP for the standard version of the CAPM are sometimes significantly different to those from the Ibbotson method. The Lally method has not yet been applied to New Zealand data. This paper applies the Lally (2002) method to New Zealand data over the period 1960-2005.

The Lally method is closest in spirit to the Ibbotson method. Although the former estimates the unlevered MRP first and then corrects it for market leverage, whereas the latter estimates the levered MRP directly, both require the arithmetic average of historical data. If companies that comprise the market portfolio do not have any debt, the unlevered MRP will equal the levered MRP. In other words, for a market without leverage, the Ibbotson and the Lally estimates of the MRP will be identical. Furthermore, even in the presence of debt, the Ibbotson and Lally estimates of the MRP will still be identical if market leverage is constant over time.

In addition, previous applications of various approaches to estimating the MRP in New Zealand (see Table 2.1) show that the results from applying the Ibbotson method are relatively stable, in contrast to those from the DDM and the Merton (1980) methods. The New Zealand estimates of the Ibbotson MRP range from 5.5\% to 6.5\% in the standard CAPM. Lally (2001) finds that the three-stage version of the DDM yields a range of the estimated MRP from 3.8\% to 5.9\%. Boyle (2005) applies the Merton method to New Zealand data, and yields a range from $0.9 \%$ to $33.6 \%$. The results 
from applying the Siegel method vary within the range of $1 \%$ over time, and do not differ substantially from the Ibbotson estimates. This implies that New Zealand estimates of the Ibbotson MRP are not seriously biased due to inflation. ${ }^{3}$

In view of these points, we seek to compare results from the timevarying approach of Lally (2002) with those from the historical averaging approach of Ibbotson and Sinquefield (1976). Chapter 3 discusses the application of both the Ibbotson and the Lally (2002) methods to New Zealand data over the period 1960-2005. Chapter 4 presents the results.

Table 2.1: Previous Estimates of the MRP in New Zealand

\begin{tabular}{|c|c|c|c|c|}
\hline Author & CAPM & Method & $\begin{array}{l}\text { MRP } \\
\text { Estimate }\end{array}$ & Period \\
\hline Chay et al. (1993) & Standard & Ibbotson & $6.2 \%$ & 1931-92 \\
\hline Chay et al. (1995) & Standard & Ibbotson & $6.5 \%$ & 1931-94 \\
\hline Lally (2001) & Standard & $\begin{array}{l}\text { Three-stage } \\
\text { version of the } \\
\text { DDM }\end{array}$ & $3.8 \%-5.9 \%$ & 2001 \\
\hline Lally and Marsden (2004b) & Standard & Ibbotson & $5.5 \%$ & 1931-2002 \\
\hline Lally and Marsden (2004b) & $\begin{array}{l}\text { Brennan- } \\
\text { Lally }\end{array}$ & Ibbotson & $7.2 \%$ & 1931-2002 \\
\hline Lally and Marsden (2004a) & $\begin{array}{l}\text { Brennan- } \\
\text { Lally }\end{array}$ & Siegel & $5.5 \%-6.2 \%$ & 1931-2002 \\
\hline Boyle (2005) & Standard & Merton & $0.9 \%-33.6 \%$ & 1970-2003 \\
\hline Marsden (2005) & $\begin{array}{l}\text { Brennan- } \\
\text { Lally }\end{array}$ & Siegel & $6 \%-6.8 \%$ & 1931-2004 \\
\hline
\end{tabular}

\footnotetext{
${ }^{3}$ Table 2.1 does not include the results from applying the survey evidence approach, nor unpublished work (e.g. CSFB, 1998; PwC, 2002).
} 


\section{Chapter 3}

\section{Method and Data}

The previous chapter has introduced various approaches to estimating the market risk premium. This chapter applies the historical averaging approach of Ibbotson and Sinquefield (1976) and the time-varying approach of Lally (2002) to New Zealand data over the period 1960-2005. In the standard CAPM, the application of the Ibbotson MRP estimator requires two data sets: market returns and risk free rates of return. The application of the Lally MRP estimator requires an additional three data sets: market debt, market equity, and the returns on corporate bonds. In the simplified Brennan-Lally version of the CAPM, the application of the two estimators requires another five data sets: cash dividend yields, the market value weights of investors who hold shares directly (as opposed to via superannuation funds and unit trusts), the market value weighted averages of the marginal ordinary tax rates faced by individual investors in shares, the proportion of dividends that were not generally tax-free, and company tax rates. These five data sets are available from Lally and Marsden (2004b). This chapter first describes the methods to estimate the two MRP estimators in both the standard CAPM and the simplified Brennan-Lally version of the CAPM. It then discusses the collection processes for the five data sets required under the standard CAPM. This chapter also discusses data issues and how they were addressed. A Miller (1977) tax world, where 
debt policy has no effect on a company's value but an equilibrium level of corporate debt still exists in the economy, is assumed to prevail throughout this paper.

\subsection{The Ibbotson MRP Estimator}

The Ibbotson MRP estimator presumes that the true MRP does not change over time. In the standard version of the CAPM, it estimates the MRP by arithmetically averaging the historical annual excess return over the sample period:

$$
\begin{aligned}
M \hat{R} P_{I} & =\overline{R_{m}-R_{f}} \\
& =\bar{R}_{m}-\bar{R}_{f}
\end{aligned}
$$

where

$$
\begin{aligned}
M \hat{R} P_{I} & =\text { Ibbotson estimate of the MRP } \\
R_{m} & =\text { return on the market portfolio } \\
R_{f} & =\text { risk free rate of return. }
\end{aligned}
$$

Since previous studies, such as Chay et al. $(1993,1995)$ and Lally and Marsden (2004b), have used the Ibbotson method to estimate the MRP for New Zealand in the standard CAPM, the data sets for $R_{m}$ and $R_{f}$ were easily obtained. With the market portfolio being proxied by an equity portfolio (as usual), the market return was therefore the return on this equity portfolio. The risk free rate was proxied by the yield on long-term government bonds.

In the Brennan-Lally version of the CAPM, the Ibbotson estimate of the MRP is generated as follows:

$$
\begin{aligned}
M \hat{R} P_{I} & =\overline{R_{m}-D_{m} T_{m}-R_{f}\left(1-T_{I}\right)} \\
& =\bar{R}_{m}-\overline{D_{m} T_{m}}-\overline{R_{f}\left(1-T_{I}\right)}
\end{aligned}
$$

where 


$$
\begin{aligned}
& D_{m}=\quad \begin{array}{l}
\text { cash dividend yield (excluding imputation } \\
\text { credits) on the market portfolio }
\end{array} \\
& T_{m}=\quad \begin{array}{l}
\text { weighted average over investors of } \frac{t_{d i}-t_{g i}}{1-t_{g i}} \text { with } \\
\text { weights } x_{i}, \text { where } t_{d i}=\text { investor } i \text { 's tax rate on } \\
\text { cash dividends from the market portfolio, and } \\
t_{g i}=\text { investor } i^{\prime} \text { s tax rate on capital gains }
\end{array} \\
& T_{I}=\quad \begin{array}{l}
\text { weighted average over investors of } \frac{t_{i}-t_{g i}}{1-t_{g i}} \text { with } \\
\text { weights } x_{i}, \text { where } t_{i}=\text { investor } i^{\prime} \text { s tax rate on }
\end{array} \\
& \begin{array}{l}
\text { interest } \\
x_{i}=\quad
\end{array} \\
& w_{i}=\quad \begin{array}{l}
\left(1-t_{g i}\right) \\
\text { market value weight of investor } i .
\end{array}
\end{aligned}
$$

The time series data for $D_{m}$ are observable. Those for $T_{m}$ and $T_{I}$ have to be estimated. Due to tax changes in 1988, the estimates of $T_{m}$ and $T_{I}$ are generated in a different way from 1988. So, we broke down the study period into two sub periods: $1960-87$ and 1988-2005.

Following Lally and Marsden (2004b), $T_{m}$ and $T_{I}$ for each year in the period 1960-87 are as follows ${ }^{1}$ :

$$
\begin{aligned}
T_{m t} & =w_{A t} T_{0 t} p_{t} \\
T_{I t} & =w_{A t} T_{0 t},
\end{aligned}
$$

where

${ }^{1}$ Lally and Marsden (2004b) classify New Zealand investors into two groups, with type A investors being defined as those who own equities directly and type B investors being defined as those who own equities via superannuation funds and unit trusts. 


$$
\begin{aligned}
& w_{A t}=\text { year } t \text { market value weight of type } \mathrm{A} \text { investors } \\
& \text { (who hold shares directly as opposed to via su- } \\
& \text { perannuation funds and unit trusts) } \\
& T_{0 t}=\text { year } t \text { market value weighted average of the } \\
& \text { marginal ordinary tax rates faced by individual } \\
& \text { investors in shares } \\
& p_{t}=\text { proportion of dividends that were not generally } \\
& \text { tax-free in year } t \text {. }
\end{aligned}
$$

Following Lally and Marsden (2004b), $T_{m}$ and $T_{I}$ for each year in the period 1988-2005 are as follows:

$$
\begin{aligned}
T_{m t}= & T_{I t}-\left(1-T_{I t}\right) Q_{m t} \\
T_{I t}= & \text { year } t \text { weighted average over investors of } \frac{t_{i}-t_{g i}}{1-t_{g i}} \\
& \text { with weights } x_{i},
\end{aligned}
$$

where $Q_{m t}$ is the ratio of imputation credits to cash dividends for year $t$.

The simplified Brennan-Lally version of the CAPM assumes that capital gains taxes are zero for all investors $\left(t_{g i}=0\right)$. So, $x_{i}=w_{i}$. Consequently, for 1988-2005:

$$
\begin{aligned}
T_{I t} & =\sum w_{i t} t_{i t} \\
& =T_{0 t} .
\end{aligned}
$$

The simplified Brennan-Lally version also assumes that imputation credits are attached at the maximum possible rate. That means, $Q_{m t}=\frac{T_{c t}}{1-T_{c t}}$, where $T_{c t}$ is the company tax rate in year $t$. Consequently, for 1988-2005:

$$
\begin{aligned}
T_{m t} & =T_{I t}-\left(1-T_{I t}\right) \frac{T_{c t}}{1-T_{c t}} \\
& =T_{0 t}-\left(1-T_{0 t}\right) \frac{T_{c t}}{1-T_{c t}} .
\end{aligned}
$$




\subsection{The Lally MRP Estimator}

Lally (2002) theoretically derives the relation between the MRP and market leverage from Modigliani and Miller (MM) proposition II. The ex-post counterpart to a generalisation of MM proposition II is: ${ }^{2}$

$$
R_{m t}=R_{m t}^{u}\left[1+\frac{B_{m t}}{S_{m t}}(1-\alpha)\right]-R_{d t} \frac{B_{m t}}{S_{m t}}(1-\alpha)
$$

where

$$
\begin{aligned}
R_{m t}= & \text { return on the market portfolio in year } t \\
R_{m t}^{u}= & \text { unlevered return on the market portfolio in year } t \\
B_{m t}= & \text { market debt (aggregate debt of companies comprising } \\
& \text { the market portfolio) in year } t \\
S_{m t}= & \text { market equity (aggregate equity of companies } \\
& \text { comprising the market portfolio) in year } t \\
\alpha= & \text { parameter reflecting tax and debt policy } \\
R_{d t}= & \text { return on corporate bonds in year } t .
\end{aligned}
$$

In a Miller (1977) tax world (i.e. $\alpha=0$ ), equation 3.1 can be simplified to:

$$
R_{m t}=R_{m t}^{u}\left(1+\frac{B_{m t}}{S_{m t}}\right)-R_{d t} \frac{B_{m t}}{S_{m t}} .
$$

Subtracting the risk free rate from both sides gives:

$$
\begin{aligned}
R_{m t}-R_{f t} & =R_{m t}^{u}\left(1+\frac{B_{m t}}{S_{m t}}\right)-R_{d t} \frac{B_{m t}}{S_{m t}}-R_{f t} \\
& =R_{m t}^{u}\left(1+\frac{B_{m t}}{S_{m t}}\right)-R_{d t} \frac{B_{m t}}{S_{m t}}-R_{f t}\left(1+\frac{B_{m t}}{S_{m t}}-\frac{B_{m t}}{S_{m t}}\right) \\
& =\left(R_{m t}^{u}-R_{f t}\right)\left(1+\frac{B_{m t}}{S_{m t}}\right)-\left(R_{d t}-R_{f t}\right) \frac{B_{m t}}{S_{m t}} .
\end{aligned}
$$

As $R_{m t}, R_{m t}^{u}$, and $R_{d t}$ are random variables and $R_{f t}, B_{m t}$, and $S_{m t}$ are set at the beginning of each sample year, taking the expected value of both sides

${ }^{2} \alpha=T_{c}$ under a Modigliani and Miller $(1958,1963)$ world; $\alpha=0$ under a Miller (1977) world; $\alpha=\frac{R_{f} T_{c}}{1+R_{f}}$ under a Miles and Ezzell (1985) world, where $T_{c}$ represents the corporate tax rate. 
of the above equation gives:

$$
\begin{aligned}
E\left(R_{m t}-R_{f t}\right) & =E\left(R_{m t}^{u}-R_{f t}\right)\left(1+\frac{B_{m t}}{S_{m t}}\right)-E\left(R_{d t}-R_{f t}\right) \frac{B_{m t}}{S_{m t}} \\
& =M R P^{u}\left(1+\frac{B_{m t}}{S_{m t}}\right)-D R P \frac{B_{m t}}{S_{m t}} .
\end{aligned}
$$

This represents the Lally MRP in the standard version of the CAPM. The unlevered Market Risk Premium $\left(M R P^{u}\right)$ is estimated as the arithmetic mean of the annual unlevered market return in excess of the risk free rate $\left(\overline{R_{m}^{u}-R_{f}}\right)$, and the Debt Risk Premium $(D R P)$ is estimated as the arithmetic mean of the annual corporate bond return in excess of the risk free rate $\left(\overline{R_{d}-R_{f}}\right)$. Although $R_{m t}^{u}$ is unobservable, it can be estimated through restructuring equation 3.2 to:

$$
R_{m t}^{u}=\frac{R_{m t}+R_{d t} \frac{B_{m t}}{S_{m t}}}{1+\frac{B_{m t}}{S_{m t}}} .
$$

Hence, the Lally estimator for the year $T$ ( $T$ represents the last year in the sample period) MRP in the standard version of the CAPM is:

$$
M \hat{R} P_{L T}=\left(\overline{R_{m}^{u}-R_{f}}\right)\left(1+\frac{B_{m T}}{S_{m T}}\right)-\left(\overline{R_{d}-R_{f}}\right) \frac{B_{m T}}{S_{m T}} .
$$

The Lally MRP in the simplified Brennan-Lally version of the CAPM can be estimated by first subtracting $D_{m t} T_{m t}+R_{f t}\left(1-T_{I t}\right)$ from both sides of equation 3.2:

$$
\begin{aligned}
R_{m t}-D_{m t} T_{m t}- & R_{f t}\left(1-T_{I t}\right) \\
= & R_{m t}^{u}\left(1+\frac{B_{m t}}{S_{m t}}\right)-R_{d t} \frac{B_{m t}}{S_{m t}}-\left[D_{m t} T_{m t}+R_{f t}\left(1-T_{I t}\right)\right] \\
= & {\left[R_{m t}^{u}-D_{m t} T_{m t}-R_{f t}\left(1-T_{I t}\right)\right]\left(1+\frac{B_{m t}}{S_{m t}}\right) } \\
& -\left[R_{d t}-D_{m t} T_{m t}-R_{f t}\left(1-T_{I t}\right)\right] \frac{B_{m t}}{S_{m t}},
\end{aligned}
$$

and then taking the expectations of both sides:

$$
\begin{aligned}
E\left[R_{m t}-D_{m t} T_{m t}-\right. & \left.R_{f t}\left(1-T_{I t}\right)\right] \\
= & E\left[R_{m t}^{u}-D_{m t} T_{m t}-R_{f t}\left(1-T_{I t}\right)\right]\left(1+\frac{B_{m t}}{S_{m t}}\right) \\
& \quad-E\left[R_{d t}-D_{m t} T_{m t}-R_{f t}\left(1-T_{I t}\right)\right] \frac{B_{m t}}{S_{m t}} \\
= & M R P^{u}\left(1+\frac{B_{m t}}{S_{m t}}\right)-D R P \frac{B_{m t}}{S_{m t}} .
\end{aligned}
$$


Therefore, the Lally estimator for the year T MRP in the simplified BrennanLally CAPM is:

$$
M \hat{R} P_{L T}=M \hat{R} P^{u}\left(1+\frac{B_{m T}}{S_{m T}}\right)-D \hat{R} P \frac{B_{m T}}{S_{m T}}
$$

where

$$
\begin{aligned}
M \hat{R} P^{u} & =\overline{R_{m}^{u}-D_{m} T_{m}-R_{f}\left(1-T_{I}\right)} \\
D \hat{R} P & =\overline{R_{d}-D_{m} T_{m}-R_{f}\left(1-T_{I}\right)}
\end{aligned}
$$

and the formula for $R_{m t}^{u}$ is as shown in equation 3.3. Also, for each year in the period 1960-87,

$$
\begin{aligned}
T_{m t} & =w_{A t} T_{0 t} p_{t} \\
T_{I t} & =w_{A t} T_{0 t} .
\end{aligned}
$$

For each year in the period 1988-2005,

$$
\begin{aligned}
T_{m t} & =T_{0 t}-\left(1-T_{0 t}\right) \frac{T_{c t}}{1-T_{c t}} \\
T_{I t} & =T_{0 t} .
\end{aligned}
$$

The data sets for $D_{m}, w_{A}, T_{0}, p$, and $T_{c}$ for 1960-2002 were obtained from Lally and Marsden (2004b). As we require data sets for $T_{0}$ and $T_{c}$ up to 2005, we extrapolated their values in 2002 to 2003-05. The following section describes the data collection process for the five required data sets ( $R_{m}, R_{f}, B_{m}, S_{m}$, and $R_{d}$ ) in the standard CAPM and the corresponding data issues. The data sets for $B_{m}, S_{m}$, and $R_{d}$ are not as easily obtained as $R_{m}$ and $R_{f}$ in New Zealand. Approximations were required.

\subsection{Data and Data Issues}

To generate the Ibbotson and the Lally MRP estimates over the period 1960-2005, five data sets are required, including market returns $\left(R_{m}\right)$, risk 
free rates of return $\left(R_{f}\right)$, market equity $\left(S_{m}\right)$, market debt $\left(B_{m}\right)$, and the returns on corporate bonds $\left(R_{d}\right)$. The following material describes how these data sets were obtained or estimated. In summary, the data sets for $R_{m}$ and $R_{f}$ were sourced from Chay et al. (1993), although some modifications were made. Those for $S_{m}$ and $B_{m}$ were manually collected. Since the data set for $R_{d}$ was unavailable, we used the return on government bonds $\left(R_{r}\right)$ as a proxy for $R_{d}$.

\subsubsection{The Market Return}

Chay et al. (1993) provides the source of market return data. They present New Zealand data on equity returns over the period 1931-92. However, Lally and Marsden (2004b) point out that it is inappropriate to use Chay et al.'s (1993) equity return data in the standard CAPM after 1987, because Chay et al. (1993) used the New Zealand Stock Exchange gross share price index after 1987 and this includes imputation credits. Hence, their data are not appropriate to estimate the MRP in the standard CAPM.

Lally and Marsden (2004b, Appendix A) make adjustments to Chay et al.'s (1993) data to remove imputation credits. We used the equity return data suggested by Lally and Marsden (2004b) as our market return data. They are nominal gross equity returns exclusive of imputation credits over the period 1960-2005. ${ }^{3}$

\subsubsection{The Risk Free Rate}

The risk free rate of return is necessary to generate both the Ibbotson and the Lally estimates. Two steps are involved to determine the risk free rate: the first is to choose between long-term government bonds and Treasury bills (short-term government bonds) as a proxy for the risk free asset, and the second is to choose between the rate of return and the yield on these bonds.

\footnotetext{
${ }^{3}$ Nominal gross equity returns include both capital appreciation and dividend income.
} 
The type of government bonds to use as the risk free asset is arguable. Conceptually, the right choice is that corresponding to the horizon of the common investor which underlies the CAPM, but this is unobservable. More pragmatically, Dimson et al. (2000) argue that Treasury bills are closer to risk free assets, because the values of Treasury bills are less likely to be affected by changes in real interest rates and inflation expectations than long-term government bonds. In addition, investors do not always hold long-term government bonds to maturity. However, Booth (2001) argues that since yields on short-term Treasury bills are often affected by shortterm monetary policy, it is not appropriate to use them as a proxy for the risk free asset. Siegel (2005) suggests that long-term inflation-indexed government bonds are closer to risk free assets than short-term government bonds, because they provide a constant real return from a long-term perspective. In practice, the choice of government bonds usually depends on available data sources. As we were unable to obtain reliable data on New Zealand short-term government bonds, long-term (10-year) government bonds were used as a proxy for risk free assets in this paper.

Bond yields are the prospective return per year on the bond until maturity, if there is no default. Bond returns are the realised returns. Since the MRP is a forward-looking concept and bond yields are forward-looking rates, yields on government bonds were chosen rather than returns. Hence, this paper used the yield on 10-year government bonds as a proxy for the risk free rate of return.

\subsubsection{Market Leverage}

Unlike the data sets for $R_{m}$ and $R_{f}$, which are easily obtained as previous studies have compiled them, we manually collected the data sets for $B_{m}$ and $S_{m}$. We estimated market leverage as the aggregate debt of companies 
that comprise the market portfolio divided by their aggregate value:

$$
\begin{aligned}
L & =\frac{B_{m}}{B_{m}+S_{m}} \\
& =\frac{\sum_{i=1}^{N} B_{i}}{\sum_{i=1}^{N} B_{i}+\sum_{i=1}^{N} S_{i}}
\end{aligned}
$$

where

$$
\begin{aligned}
L & =\text { market leverage } \\
B_{i} & =\text { market value of company } i^{\prime} \text { s debt } \\
S_{i} & =\text { market value of company } i^{\prime} \text { 's equity } \\
& =\text { market capitalisation of company } i \\
N & =\text { number of companies included in the market portfolio. }
\end{aligned}
$$

We started by selecting an equity index to proxy for the market portfolio, and then deleted companies with relatively small market capitalisation. Only those companies whose aggregate market capitalisation makes up $80 \%$ of the total market capitalisation in the equity index were used to proxy for the market portfolio. We then collected the individual debt and equity information on the latter companies $(i=1,2, \ldots, N)$ to estimate the market leverage ratio. This process was conducted every five years over the period 1960-2005.

\section{Data Sources for the Equity Index}

The equity index plays a fundamental role in defining the composition of the market portfolio. To be consistent with our data for $R_{m}$, which were based on the equity index constructed by Chay et al. (1993), we sought to use the same equity index.

Chay et al. (1993) used four data sources to construct the equity index for New Zealand over the period 1960 to 1990: the Department of Statistics capital index (for the period before 1970), the Reserve Bank of New Zealand (RBNZ) share price index (for 1970-78), the Datex gross share price index (for 1979-86), and the New Zealand Stock Exchange (NZX) 
gross share price index (for 1987-90). However, we were unable to obtain data from Statistics New Zealand and Datex, as they have not retained the data from the relevant periods. Thus, we used the RBNZ share price index and the NZX gross share price index to construct the equity index over the period 1960 to 2005.

The RBNZ and the NZX construct their indices in a similar way. Both require listed companies to be large in size and frequently traded. In addition, the RBNZ index emphasises the reasonable representation of listed companies across New Zealand industries, although mining and oil exploration companies are excluded. Unlike the RBNZ index, which only includes New Zealand domiciled companies, the NZX index also includes some overseas companies listed in the New Zealand market.

In addition to the period from 1970-78, the RBNZ share price index was used to replace the missing data from both Statistics New Zealand (for 1960-70) and Datex (for 1979-86). Since the RBNZ share price index was only introduced in January 1968, the composition of the equity index before 1968 was based on the composition of the RBNZ index in 1968. After 1968, changes in the RBNZ index were taken into account each year.

As this paper estimated market leverage every five years, the RBNZ share price index was used in 1960, 1965, 1970, 1975, 1980, and 1985. In addition, the NZX 40 index was used in 1990, 1995, and 2000, and the NZX 50 index in 2005. ${ }^{4}$

\section{The Construction of the Market Portfolio}

Reducing the number of companies to a manageable level means that a longer time series is possible within time constraints. Instead of using all the companies in the equity index, we used a subset of all the companies included in the equity index. These companies comprise $80 \%$ of the total market capitalisation in the equity index. They were selected according to

\footnotetext{
${ }^{4}$ The NZX 50 index was launched in 2003 to replace the NZX 40 index.
} 
their weights in the equity index:

$$
W_{i}=\frac{S_{i}}{\sum_{i=1}^{M} S_{i}}
$$

where

$$
\begin{aligned}
W_{i}= & \text { index weight of company } i \\
S_{i}= & \text { market capitalisation of company } i \\
M= & \text { number of companies included in the equity index, } \\
& \text { and } M>N
\end{aligned}
$$

Table 3.1 shows the results from our selection process. The number of companies that comprise the market portfolio proxy as a proportion of the number included in the equity index $\left(\frac{N}{M}\right)$ is smallest in 1995 and 2005: 30\% and 32\% respectively. Hence, we chose the 1995 and the 2005 cases to test whether the use of a subset of the equity index has materially affected the accuracy of the results.

Table 3.1: Number of Companies in the Market Portfolio Proxy and the Equity Index

\begin{tabular}{lllllllllll} 
Year & 1960 & 1965 & 1970 & 1975 & 1980 & 1985 & 1990 & 1995 & 2000 & 2005 \\
\hline
\end{tabular}

\begin{tabular}{ccccccccccc}
$N$ & 16 & 23 & 20 & 22 & 19 & 24 & 23 & 12 & 20 & 16 \\
$M$ & 40 & 51 & 58 & 57 & 53 & 56 & 40 & 40 & 40 & 50 \\
$\frac{N}{M}$ & $40 \%$ & $45 \%$ & $34 \%$ & $39 \%$ & $36 \%$ & $43 \%$ & $58 \%$ & $30 \%$ & $50 \%$ & $32 \%$ \\
\hline
\end{tabular}

Notes: the RBNZ Share Price Index included 57 companies at the beginning of 1968 . Among these 57 companies, 51 companies were listed on the New Zealand Stock Exchange in 1965 and 40 companies were listed in 1960.

Table 3.2 shows the sensitivity of the estimates of market leverage in 1995 and 2005 to increasing the percentage of index value captured to $90 \%$ and $100 \%$. In 1995, if we were to use companies with a cumulative index weight of $100 \%$ rather than $80 \%$ to determine the market portfolio, 
estimated market leverage would fall by $2 \%$. If we were to use companies with a cumulative index weight of $90 \%$, estimated market leverage would decrease by $1 \%$. In 2005, a cumulative index weight of $100 \%$ results in an increase in estimated market leverage by $1 \%$ and a cumulative index weight of $90 \%$ results in an increase in estimated market leverage by $2 \%$. These differences do not significantly affect the results in this paper. Hence, a cumulative index weight of $80 \%$ is reasonable for the construction of market portfolios in this paper.

Table 3.2: Estimated Market Leverage and Cumulative Index Weights

\begin{tabular}{llll} 
Year & $\sum_{i=1}^{N} W_{i}=80 \%$ & $\sum_{i=1}^{N} W_{i}=90 \%$ & $\sum_{i=1}^{N} W_{i}=100 \%$ \\
\hline & & & \\
1995 & 0.39 & 0.38 & 0.37 \\
2005 & 0.34 & 0.36 & 0.35 \\
\hline
\end{tabular}

\section{Estimation of Market Leverage}

After specifying the composition of the market portfolio every five years, we estimated market equity $\left(S_{m}\right)$ by adding up the market capitalisation of companies that comprise the market portfolio proxy. The market capitalisation data for individual companies are indicated in National Business Review for 1985 and the NZX equity indices for 1990, 1995, 2000, and 2005. The remaining market capitalisation data were obtained from the Official Record of New Zealand Stock Exchange for 1960, 1965, 1970, 1975 and 1980. As the Official Record does not give the market capitalisation data directly, we calculated market capitalisation by multiplying the number of a company's shares on issue by their last trading price.

We estimated market debt $\left(B_{m}\right)$ by adding up the market values of the debt of companies comprising the market portfolio. As debt is not in general traded, the book value of debt was used as a proxy for its market 
value (see Appendix A). Information on the book value of a company's debt was obtained from its consolidated balance sheet, which is included in the company's Annual Report. Only interest-bearing debt was taken into account. Examples include bank overdrafts, loans, advances, debentures, commercial paper, etc. Other liabilities, such as trade or short-term creditors, represent deferred payments for goods or services and were not included in our calculation. Provisions and contingent liabilities are also not interest bearing, and were also excluded from the calculation.

After obtaining the values of market equity and market debt, we were able to estimate market leverage through $L=\frac{B_{m}}{B_{m}+S_{m}}$. The results are shown in Table 3.3. The following section discusses various data issues that arise from the estimation of market leverage.

Table 3.3: Market Equity, Market Debt and Market Leverage

\begin{tabular}{ccccccccccc} 
Year & 1960 & 1965 & 1970 & 1975 & 1980 & 1985 & 1990 & 1995 & 2000 & 2005 \\
\hline $\begin{array}{c}S_{m} \\
(\$ \mathrm{~m})\end{array}$ & 209 & 469 & 875 & 919 & 1953 & 7884 & 13401 & 43369 & 34731 & 38790 \\
$B_{m}$ & & & & & & & & & & \\
$(\$ \mathrm{~m})$ & 70 & 146 & 268 & 825 & 1688 & 5552 & 39976 & 24386 & 21511 & 18932 \\
& & & & & & & & & & \\
$L$ & 0.25 & 0.24 & 0.23 & 0.47 & 0.46 & 0.42 & 0.75 & 0.37 & 0.38 & 0.33 \\
\hline
\end{tabular}

\subsubsection{Data Issues for Market Leverage}

\section{Missing Data}

Where the essential information of a company was unavailable, this company could not be used. The annual reports of some companies were missing. Consequently, we could not obtain the debt information for these companies, and were forced to remove them from the market portfolio proxy. To ensure that the cumulative index weight of companies com- 
prising the market portfolio proxy remained at $80 \%$, substitute companies were added to the market portfolio proxy. These substitute companies were those which were deleted earlier in the process due to their low index weight; companies with a relatively high market value took priority.

The problem of missing data was not significant, except in 1990. In 1990, the top 13 companies in the equity index had a cumulative weight of $84.83 \%$. However, five of them had missing annual reports. Removing these five companies reduced the cumulative weight to $68.72 \%$. To raise the cumulative weight to $80 \%, 15$ substitute companies were added. However, among these 15 companies, the annual reports of two companies could not be found. This reduced the cumulative index weight to $78.94 \%$. Therefore, another three companies were added in substitution. As a result, 24 companies were selected from the NZX 40 index to proxy for the market portfolio in 1990.

\section{Time Differences between Debt and Equity Valuations}

As the estimation of market leverage requires both debt and equity data, they must be consistent in terms of time. However, there were significant time gaps between debt and equity values for some companies. This is because the equity data was collected at the same point in time for all companies for a given year whereas the debt data was obtained from companies' annual reports, and it is common for different companies to have different balance dates. Hence, it is necessary to adjust the date of debt data towards the date of equity data, whenever the time gap is significant.

One possibility to reduce the time gap for some companies is to look at their half year reports. When the balance date in the annual report is substantially different to the equity valuation date, there will be a half year report that is closer to it. However, most half year reports did not provide enough detail for us to estimate the debt level of the company. Hence, the only data sources for debt were companies' annual reports.

We therefore sought to minimise the time gap by averaging over two 
balance dates. As it is impossible to exactly align the debt and the equity dates for all the companies, a time gap of no more than three months was accepted. Table 3.4 displays the dates for equity values and the corresponding ranges of balance dates within which debt values were used.

Table 3.4: Equity Valuation Dates and Acceptable Balance Dates

\begin{tabular}{llll} 
Sample Period & Period before 1985 & 1985 & Period after 1985 \\
\hline $\begin{array}{l}\text { Equity Valuation } \\
\text { Dates }\end{array}$ & 1 Feb & 6 May & $28,29,30$ December \\
Balance Dates & $\begin{array}{l}\text { 1 Nov (previous year) } \\
\text {-1 May }\end{array}$ & 1 Feb -1 Aug & $\begin{array}{l}\text { 30 Sep-31 Mar } \\
\text { (following year) }\end{array}$ \\
\hline
\end{tabular}

Our equity values were obtained as at the 1st of February for the period before 1985, the 6th of May for 1985, and the end of December for the period after 1985. Hence, for the period before 1985, any consolidated balance sheet with a balance date between the 1st of November in the previous year and the 1st of May in the current year was used to obtain the debt level of the company; in 1985 any consolidated balance sheet with a balance date between early February and early August was used; for the period after 1985, any consolidated balance sheet with a date between the end of September in the current year and the end of March in the following year was used.

For balance dates outside the ranges stated in Table 3.4, adjustments were made to the raw debt data. Figure 3.1 displays the adjustment under Method One, which averages over the debt levels. Whenever the time difference between the equity valuation date and the balance date is more than three months, debt levels for a company are averaged over two adjoining balance dates. Figure 3.2 displays the adjustment under Method Two, which averages over the individual debt to equity ratios, i.e., whenever the time difference is more than three months, individual debt to equity ratios are averaged over two balance dates. 


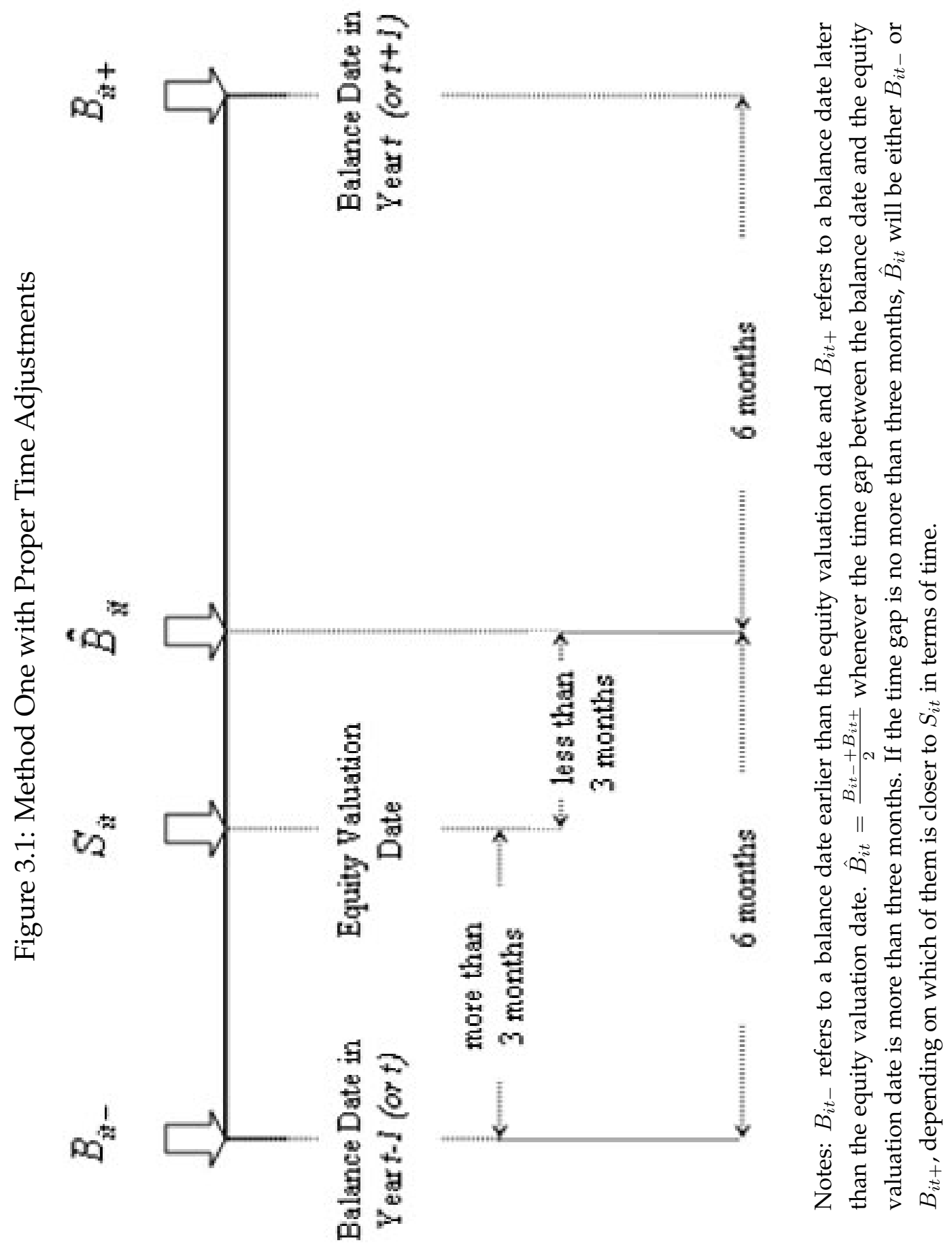




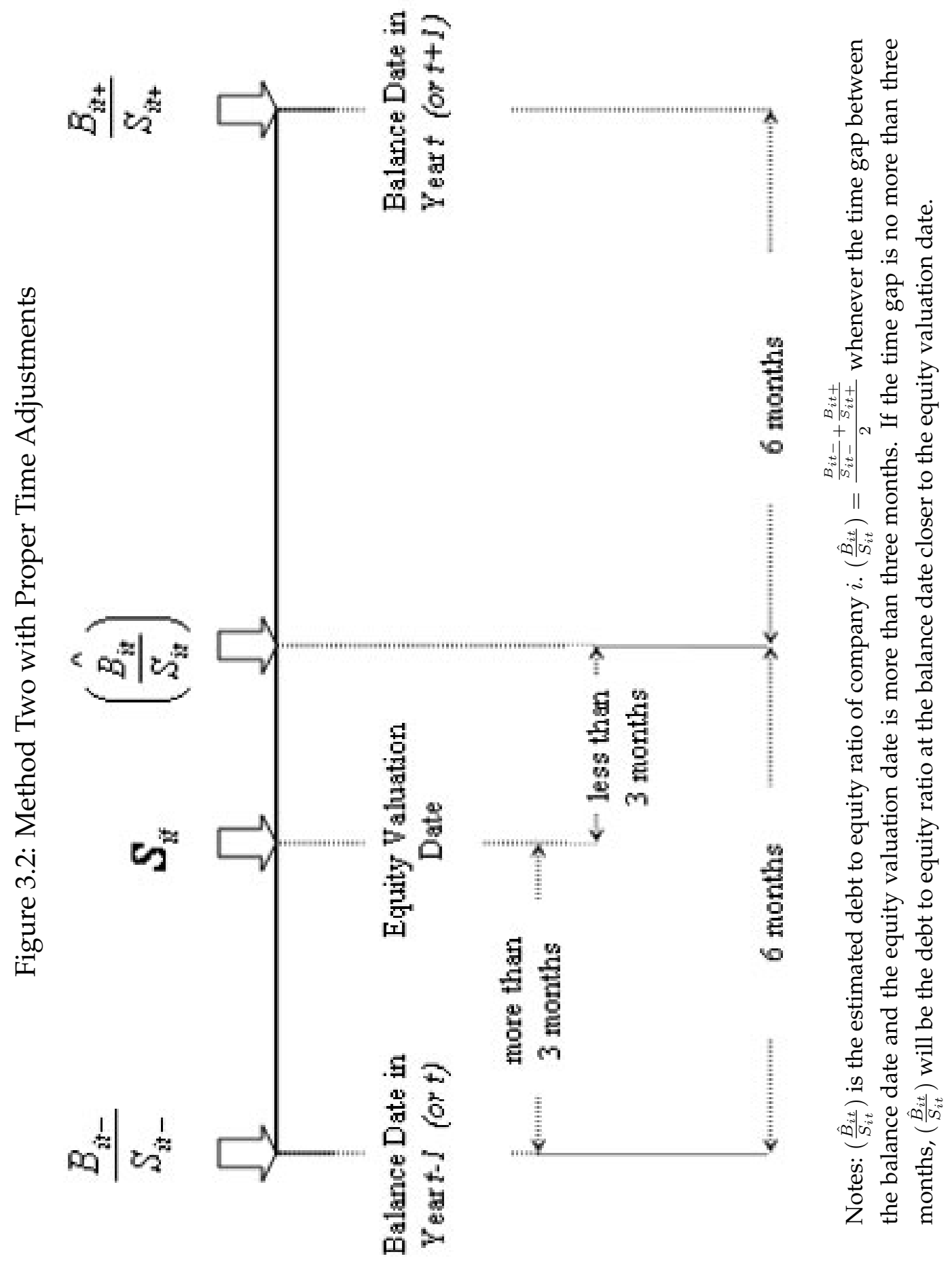


For example, if a company has a balance date on the 30th of June every year, averaging its debt levels (the adjustment under Method One) or debt to equity ratios (the adjustment under Method Two) over 30th June 1990 and 30th of June 1991 gives an estimated debt level or debt to equity ratio on 30th December 1990, which matches the equity valuation date in 1990.

These two methods are mathematically identical whenever debt and equity are valued on the same date. Method One estimates market leverage as:

$$
\hat{L_{1}}=\frac{\sum_{i=1}^{N} B_{i}}{\sum_{i=1}^{N} B_{i}+\sum_{i=1}^{N} S_{i}} .
$$

Method Two estimates market leverage as:

$$
\begin{aligned}
\frac{\hat{L_{2}}}{1-\hat{L_{2}}} & =\sum_{i=1}^{N}\left(\frac{B_{i}}{S_{i}} \times W_{i}\right) \\
& =\sum_{i=1}^{N}\left(\frac{B_{i}}{S_{i}} \times \frac{S_{i}}{\sum_{i=1}^{N} S_{i}}\right) \\
& =\frac{\sum_{i=1}^{N} B_{i}}{\sum_{i=1}^{N} S_{i}} \\
& =\frac{\hat{L_{1}}}{1-\hat{L_{1}}} .
\end{aligned}
$$

Table 3.5 compares the estimates of market leverage under these two methods for 2005, with and without time adjustments. It shows that making proper time adjustments under Method One or Method Two leads to very similar estimates of market leverage. With time adjustments, the difference between the estimates of market leverage under Method One and under Method Two is 0.0003. Without time adjustments, the difference is 0.0185. ${ }^{5}$ Thus, time adjustments are desirable but the choice of Method One or Method Two is immaterial. This paper used the results from Method One.

\footnotetext{
${ }^{5}$ The term "Without Adjustments" means we did not average individual debt levels or debt to equity levels over two balance dates even when the time gap was more than three months. We simply used the debt data from the consolidated balance sheet with
} 
Table 3.5: Estimates of Market Leverage in 2005 with and without Adjustments

Time Adjustments

No Time Adjustment

\begin{tabular}{llll} 
Method One & Method Two & Method One & Method Two \\
\hline & & & \\
0.3358 & 0.3361 & 0.3260 & 0.3075
\end{tabular}

\section{Minority Interests}

Minority interests usually exist in a company's consolidated balance sheet. They represent the shares owned by outsiders (rather than the parent company) in a company's subsidiaries. For example, the consolidated balance sheet of Alex Harvey Industries in 1985 showed minority interests of \$49 million. This means that $\$ 49$ million of the net assets of its subsidiaries are owned by outside shareholdings of the subsidiary companies. The issue of minority interests arises because the consolidated balance sheets were used to determine the debt levels, so as to avoid situations in which the leverage changes purely through a company forming a subsidiary.

We estimated market equity value by adding up the market capitalisation of companies comprising the market portfolio, and market capitalisation relates to the ordinary shares on issue for the parent company. So the resulting market equity is for all the parent companies in the market portfolio. However, market debt was estimated from companies' consolidated balance sheets and hence is for all the consolidated companies. This incon-

the date closest to the equity valuation date. For example, if a company's balance date is 30th August and the equity valuation date is 30th December, the consolidated balance sheet in the current year will be used rather than the one in the following year. Whenever the consolidated balance sheets surrounding the equity valuation date were equidistant, we used the first of these two balance dates. 
sistency will result in an overestimation of market leverage. If the value of minority interests is significant, the overestimation of leverage will be significant. So, we need to estimate the market value of the minority interests' equity and consider adding it to that of the parent company.

To estimate the market value of the minority interests' equity, we proceed as follows. For a given consolidated company $i$, let:

$$
\begin{aligned}
S_{M i}^{b} & =\text { book value of minority interests } \\
S_{P i}^{b} & =\text { book value of the parent company's equity } \\
S_{M i}^{b}+S_{P i}^{b} & =\text { book value of total shareholders' funds } \\
S_{M i}^{m} & =\text { market value of minority interests } \\
S_{P i}^{m} & =\text { market value of the parent company's equity } \\
S_{M i}^{m}+S_{P i}^{m} & =\text { market value of total shareholders' funds. }
\end{aligned}
$$

\begin{tabular}{|c|c|c|c|}
\hline & $\mathrm{NZ} \$ \mathrm{~m}$ & & $\mathrm{NZ} \$ \mathrm{~m}$ \\
\hline Equity & & Assets & 11,799 \\
\hline \multicolumn{4}{|l|}{ Ordinary Division Attributed } \\
\hline Equity and Capital Funds & 3,889 & & \\
\hline Minority Equity & $\underline{1,950}$ & & \\
\hline \multicolumn{4}{|l|}{ Total Ordinary Division Attributed } \\
\hline Equity and Capital Funds & 5,839 & & \\
\hline Liability & $\underline{5,960}$ & & 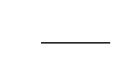 \\
\hline Total Ordinary Division Attributed & & Total Ordinary Division & \\
\hline Liabilities and Equity & 11,799 & Attributed Assets & 11,799 \\
\hline
\end{tabular}

Table 3.6: Consolidated Balance Sheet of Fletcher Challenge Ordinary Division in December 1995

Table 3.6 provides an example of a company's consolidated balance sheet. The ratio of the book value of minority interests to the book value of total shareholders' funds for Fletcher Challenge Ordinary Division in December 1995 was: 


$$
S_{M i}^{b}:\left(S_{M i}^{b}+S_{P i}^{b}\right)=\$ 1,950 \mathrm{~m}: \$ 5,839 \mathrm{~m} \approx 1: 3 .
$$

The equity index in 1995 showed that the market capitalisation of Fletcher Challenge Ordinary Division was:

$$
S_{P i}^{m}=\$ 5,209 \mathrm{~m} \text {. }
$$

Assuming that:

$$
S_{M i}^{m}:\left(S_{M i}^{m}+S_{P i}^{m}\right)=S_{M i}^{b}:\left(S_{M i}^{b}+S_{P i}^{b}\right) \approx 1: 3,
$$

the market value of total minority interests was therefore estimated as:

$$
S_{M i}^{m}=\$ 2605 \text { million, }
$$

and the market value of equity was estimated as:

$$
S_{M i}^{m}+S_{P i}^{m}=\$ 7814 \text { million. }
$$

In this study, the proportion of the aggregate book value of minority interests to the aggregate book value of total shareholders' funds ranges from $1.01 \%$ (in 2000) to $13.76 \%$ (in 1990), as shown in table 3.7 .

Table 3.7: The Aggregate Book Value of Minority Interests to the Aggregate Book Value of Total Shareholders' Funds from 1960 to 2005

\begin{tabular}{ccccccccccc} 
Year & 1960 & 1965 & 1970 & 1975 & 1980 & 1985 & 1990 & 1995 & 2000 & 2005 \\
\hline $\begin{array}{c}\sum_{i=1}^{N} S_{M i}^{b} \\
(\$ \mathrm{~m})\end{array}$ & 1.98 & 4.61 & 12.7 & 36.4 & 139 & 413 & 2477 & 3262 & 216 & 636 \\
$\sum_{i=1}^{N}\left(S_{M i}^{b}+S_{P i}^{b}\right)$ & 157 & 325 & 525 & 1113 & 2331 & 5981 & 18003 & 25679 & 21425 & 18433 \\
$(\$ \mathrm{~m})$ & & & & & & & & & & \\
$\frac{\sum_{i=1}^{N} S_{M i}^{b}}{\sum_{i=1}^{N}\left(S_{M i}^{b}+S_{P i}^{b}\right)}(\%)$ & 1.26 & 1.24 & 2.42 & 3.27 & 5.96 & 6.90 & 13.76 & 12.70 & 1.01 & 3.45 \\
\hline
\end{tabular}

As the value of $\frac{\sum_{i=1}^{N} S_{M i}^{b}}{\sum_{i=1}^{N}\left(S_{M i}^{b}+S_{P i}^{b}\right)}$ is significant, especially in 1990 and 1995, we included the aggregate value of minority interests in the aggregate market value of companies. Let: 


$$
\begin{aligned}
& a=\frac{\sum_{i=1}^{N} S_{M i}^{b}}{\sum_{i=1}^{N}\left(S_{M i}^{b}+S_{P i}^{b}\right)}=\frac{\sum_{i=1}^{N} S_{M i}^{b}}{\sum_{i=1}^{N} S_{M i}^{b}+\sum_{i=1}^{N} S_{P i}^{b}} \\
& b=\frac{\sum_{i=1}^{N} S_{M i}^{m}}{\sum_{i=1}^{N}\left(S_{M i}^{m}+S_{P i}^{m}\right)}=\frac{\sum_{i=1}^{N} S_{M i}^{m}}{\sum_{i=1}^{N} S_{M i}^{m}+\sum_{i=1}^{N} S_{P i}^{m}} .
\end{aligned}
$$

Assuming that $a$ is always equal to $b$ :

$$
b=\frac{\sum_{i=1}^{N} S_{M i}^{m}}{\sum_{i=1}^{N} S_{M i}^{m}+\sum_{i=1}^{N} S_{P i}^{m}}=a,
$$

therefore,

$$
\begin{aligned}
& \sum_{i=1}^{N} S_{M i}^{m}=\sum_{i=1}^{N} S_{M i}^{m} a+\sum_{i=1}^{N} S_{P i}^{m} a \\
& \sum_{i=1}^{N} S_{M i}^{m}(1-a)=\sum_{i=1}^{N} S_{P i}^{m} a \\
& \sum_{i=1}^{N} S_{M i}^{m}=\frac{a}{1-a} \sum_{i=1}^{N} S_{P i}^{m} .
\end{aligned}
$$

The aggregate market value of equity, including the aggregate market value of minority interest, is therefore:

$$
\begin{aligned}
S_{m}^{*} & =\sum_{i=1}^{N} S_{P i}^{m}+\sum_{i=1}^{N} S_{M i}^{m} \\
& =\sum_{i=1}^{N} S_{P i}^{m}+\frac{a}{1-a} \sum_{i=1}^{N} S_{P i}^{m} \\
& =\left(1+\frac{a}{1-a}\right) \sum_{i=1}^{N} S_{P i}^{m} \\
& =\left(1+\frac{a}{1-a}\right) S_{m} .
\end{aligned}
$$

This adjustment increased the value of market equity from $S_{m}$ to $S_{m}^{*}$, which correspondingly reduced the market leverage estimate from $\hat{L}$ to $\hat{L}^{*}$. The equation for market leverage becomes:

$$
\hat{L}^{*}=\frac{B_{m}}{B_{m}+S_{m}^{*}}=\frac{B_{m}}{B_{m}+\left(1+\frac{a}{1-a}\right) S_{m}}=\frac{B_{m}}{V_{m}+\frac{a}{1-a} S_{m}} .
$$

Table 3.8 shows the estimates of market leverage with and without consideration of minority interests. The adjustments made to the estimated market equity overcome the problem of an upward bias to market leverage. 
Table 3.8: Estimated Market Leverage With and Without Consideration of Minority Interests

\begin{tabular}{lcccccccccc} 
Year & 1960 & 1965 & 1970 & 1975 & 1980 & 1985 & 1990 & 1995 & 2000 & 2005 \\
\hline & & & & & & & & & & \\
$\hat{L}$ & 0.25 & 0.24 & 0.24 & 0.48 & 0.48 & 0.44 & 0.78 & 0.39 & 0.38 & 0.34 \\
$\hat{L}^{*}$ & 0.25 & 0.24 & 0.23 & 0.47 & 0.46 & 0.42 & 0.75 & 0.37 & 0.38 & 0.33 \\
$a(\%)$ & 1.26 & 1.42 & 2.42 & 3.27 & 5.96 & 6.90 & 13.76 & 12.70 & 1.01 & 3.45 \\
\hline
\end{tabular}

Notes: $\hat{L}^{*}$ is the market leverage estimate that considers minority interests.

\section{Convertible Notes}

Convertible notes have the attributes of both equity and debt. Convertible notes are interest-bearing debt prior to maturity. At maturity, they may be converted into ordinary shares, and hence become equity. If convertible notes are counted as debt instead of equity for all companies, the market debt level will be overestimated and the market equity level underestimated, and vice versa. Some studies, such as Brigham (1966), focus on how to break down the value of convertible notes into equity and debt.

This paper faced the issue of convertible notes at two levels. The first level refers to the convertible notes held by companies that comprise the market portfolio (see Table 3.9). The second level refers to the convertible notes included in the equity index (see Table 3.10). 

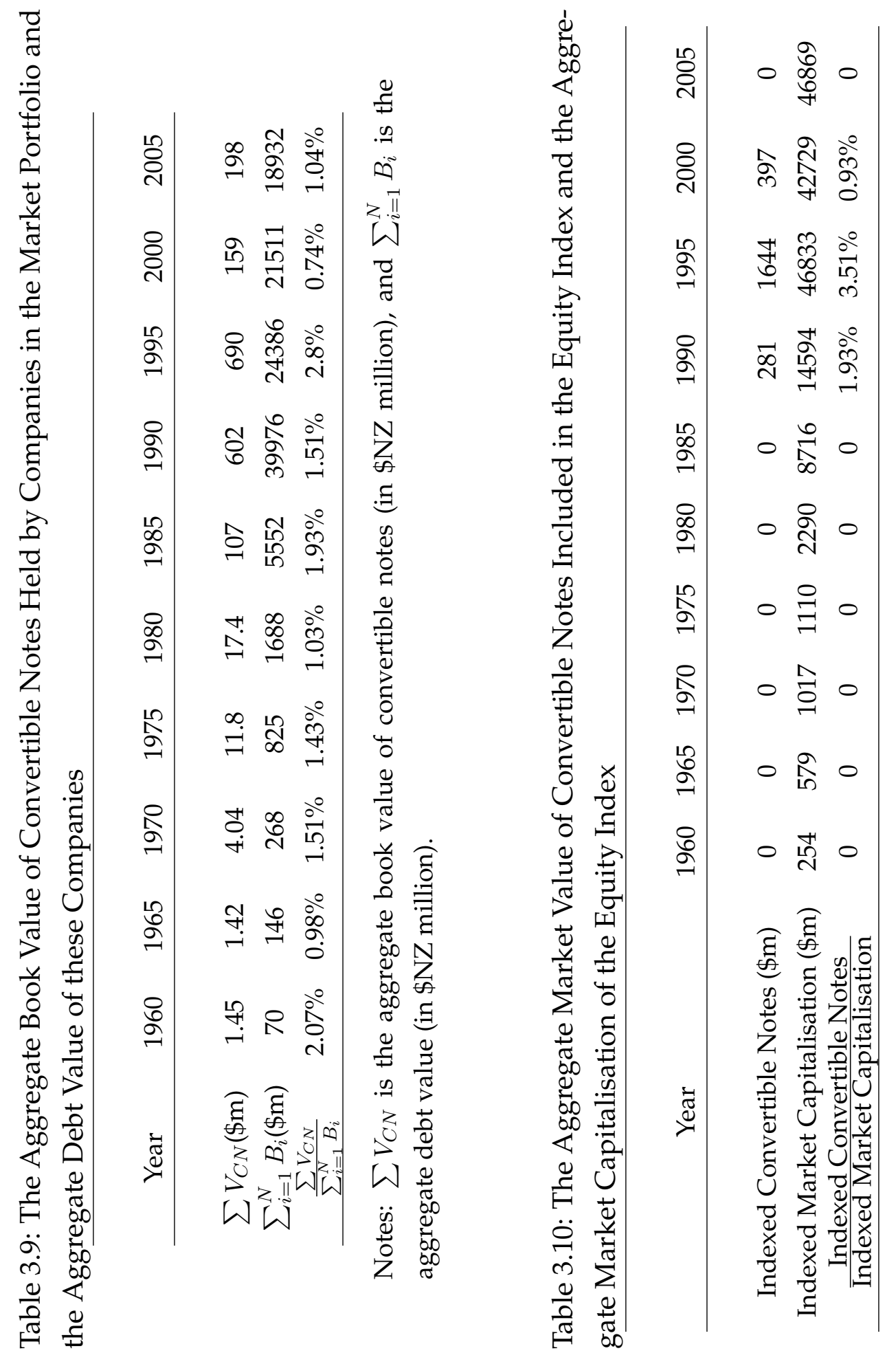
In Table 3.9, we calculated the ratio of the convertible notes held by companies in the market portfolio to their aggregate debt. It shows that the aggregate value of these convertible notes is a tiny fraction of the aggregate debt. Thus, classifying all convertible notes as debt would not substantially alter the estimate of market leverage.

Table 3.10 shows the convertible notes in the equity index as a proportion of the aggregate market capitalisation of the index. Although the recently published NZX Equity Indices Methodology Overview indicates that convertible notes are no longer eligible for inclusion in its equity indices, the NZX 40 index in 1990, 1995 and 2000 contained some convertible notes, due to changes in the NZX index criteria over time. In these three years, the aggregate value of convertible notes in the index was a small fraction of the market equity. Thus, classifying these convertible notes as equity would not substantially alter the results.

Since the aggregate value of convertible notes is insignificant both at the individual company level and at the equity index level, the existence of convertible notes is not a material issue in this paper.

\section{Inconsistencies in Shares on Issue}

The NZX equity index sometimes shows the number of ordinary shares on issue different to the figure indicated in a company's annual report. This apparent inconsistency is significant for the data in 2000 and 2005, although data in earlier sample years do not seem to have this issue. The main reason for the apparent inconsistency is the listing status of companies in the index, which is one of the elements in deciding the number of shares to be included in the NZX index. ${ }^{6}$ The NZX classifies issuers

\footnotetext{
${ }^{6}$ The Modified Free Float Methodology is another element. Indexed shares can be either NZ Shares Issued or NZ Free Float Shares depending on the thresholds for an issuer's NZ Free Float Market Capitalisation ( [NZ Free Float Shares (latest)] $\times$ [Average Daily Adjusted Closing Price (6 months)] ). There are three thresholds in terms of NZ free float market capitalisation (upper, middle and lower). As we selected companies with a
} 
into three groups according to their listing status: New Zealand listed issuers, dual listed issuers, and overseas listed issuers. New Zealand listed issuers are those who treat the NZX as their Home Exchange. They are mainly New Zealand companies. Dual and overseas listed issuers are those who treat a recognised overseas Exchange as their Home Exchange and are listed on both the NZX and their Home Exchange. Foreign issuers can choose to be listed as a dual or an overseas listed issuer on the NZX. A significant difference between a dual listed issuer and an overseas listed issuer is that the former has to comply with the listing rules of both exchanges (although some exemptions have been made due to equivalent listing rules), but the latter does not (with some exceptions). Besides that, being a dual listed issuer or an overseas listed issuer affects the index weighting of its shares.

For New Zealand listed issuers, the number of indexed shares equals the number of shares on issue at that time. Examples include Telecom Corporation of NZ Limited and Contact Energy Limited. Of course, there could still be slight difference between the number of shares included in the index and the number of shares on issue as shown in the annual report closest to the date on which the market capitalisation was observed. For example, the annual report of Donaghys Ltd shows 31.5 million ordinary shares on issue on 30 June 1990 and 32.6 million ordinary shares on issue on 30 June 1991. The NZX index in December 1990 shows 32.2 million indexed shares. Thus, for New Zealand listed issuers, the apparent inconsistency in shares on issue is mainly due to the time difference and is generally insignificant.

For dual listed issuers, the number of indexed shares equals:

cumulative index weight of $80 \%$ to constitute the market portfolio, all of them are above the middle threshold and more than half are above the upper threshold. That implies that most of the companies in this research were included at full NZ Market Capitalisation in the index while the rest were at least close to their full NZ Market Capitalisation. Hence, NZ Shares Issued were used instead of NZ Free Float Shares as the indexed shares. 
the number of shares on issue $\times \frac{\text { revenue generated in New Zealand }}{\text { total revenue generated }}$. Examples of dual listed issuers include Promina Group Limited, and APN News and Media Limited. They are jointly listed on the NZ and Australian Stock Exchanges. The balance sheet of APN News and Media Limited on 31st December 2005 shows 478 million shares on issue. However, only 151 million shares issued are treated as indexed shares. The latter is $31.7 \%$ of the total shares on issue, representing the proportion of APN News and Media Limited's revenue generated in New Zealand. Hence, for dual listed issuers, the apparent inconsistency in shares on issue is mainly due to the difference between the revenue generated in New Zealand and the revenue generated elsewhere.

For overseas listed issuers, the number of indexed shares equals the number of shares on the New Zealand register. Overseas companies must register on the New Zealand register, if they want to operate in New Zealand through their New Zealand subsidiaries. Examples of overseas listed issuers include Guinness Peat Group, Westpac Banking Corporation, AMP, and Lion Nathan. Westpac Banking Corporation is listed on the ASX, NZX, NYSE, Tokyo Stock Exchange Inc., and other exchanges. Its consolidated balance sheet shows 1869 million shares on issue on 30th September 2005. As the balance date is within three months of the date of the NZX index, the number of shares on issue at 30th December 2005 was estimated to be 1869 million. However, the NZX index shows only 40 million shares of Westpac Banking Corporation on 30th December 2005, which is $2 \%$ of the estimated number of shares on issue. This percentage represents the proportion of Westpac Banking Corporation's shares on the New Zealand register.

As dual listed companies and overseas listed companies have some of their shares listed in a different market, if the debt level from the annual report is used in combination with the market capitalisation from the NZX index, the resulting market leverage will be overestimated. Thus, we calculated the ratio of the number of indexed shares to the number of shares 
on issue in the annual report, and applied this ratio to the debt level:

the modified debt level $=\frac{\text { the number of indexed shares }}{\text { the number of shares on issue }} \times$ debt level.

The modified debt level is then consistent with the number of shares to which the market capitalisation relates.

\section{Currency Differences}

For those overseas companies listed in the New Zealand market, their financial figures must be converted into New Zealand dollars. For example, Lion Nathan migrated to Australia on 2nd June 2000. Its financial details are therefore stated in Australia dollars in its annual report. We converted these figures to New Zealand dollars, using the appropriate exchange rate from the Reserve Bank of New Zealand. The date of the exchange rate is the one to which the NZX index relates. In the example of Lion Nathan, the exchange rate on 29th December 2000 was used.

\subsubsection{Corporate Bond Returns}

The application of the Lally MRP estimator requires the rate of return on New Zealand corporate bonds $\left(R_{d}\right)$. However, returns data on corporate bonds have not been formally maintained by organisations until recently. We obtained corporate bond return data from the NZX Corporate Bond Indices only for the period 1994-2005, and attempted to obtain data for the remaining study period from historical newspapers. This was unsuccessful. An alternative method was then adopted: using the rate of return on government bonds as a proxy for the return on corporate bonds. We tested the accuracy of this approximation with Ibbotson US data and the NZX Corporate Bond Indices. 


\section{Corporate Bond Returns from the NZX Corporate Bond Indices}

The NZX Corporate Bond Indices provide gross returns of highly rated corporate bonds, capturing both the capital movement of these bonds and the interest received from holding them. There are two types of corporate bond indices: the A Grade Corporate Bond Index and the AB Grade Corporate Bond Index. The difference between these two indices is mainly due to the credit quality of the component bonds. The A Grade requires its debt securities to have a credit rating of at least A- (if rated by Standard and Poor's) or at least A3 (if rated by Moody's). The AB Grade includes more debt securities by lowering the boundary to a credit rating of BBBor Baa3 (if rated by Standard and Poor's or Moody's respectively). Since the $\mathrm{AB}$ Grade Corporate Bond Index covers a wider range of high credit quality debt securities, it was chosen over the A Grade Corporate Bond Index for this study.

However, neither of the bond indices covers a period that is comparable to our study period: the A Grade Corporate Bond Index only covers the period from 1994, and the AB Grade Corporate Bond Index only covers the period from 2001. Hence, we used the A Grade Corporate Bond Index to estimate $R_{d}$ over the period 1994 to 2001 and the $\mathrm{AB}$ Grade Corporate Bond Index over the period 2001 to 2005.

\section{Corporate Bond Returns from Newspapers}

Since NZX Corporate Bond Indices only cover the period from 1994 to 2005, we attempted to retrieve the remaining (1960-93) historical data on NZ corporate bond returns from the local newspaper-the Dominion Post, whose copies are kept in the National Library in the form of microfilm. We expected them to contain sufficient information on corporate bonds, such as coupon rates, maturity dates, and market prices (or bond yields).

However, information on corporate bonds could only rarely be found. Only the years 1960, 1961, 1969, and 1970 contained sufficient information 
for us to estimate the corporate bond return. The remaining years, however, contained very little information on corporate bonds.

Since NZ corporate bond returns could not in general be obtained from newspapers for the years 1960-93, data from the NZX Corporate Bond Indices for the years 1994-2005 could not be used for the estimation of the MRP. Instead, they were used to test the accuracy of our approximation for the NZ corporate bond return.

\section{Approximation for NZ Corporate Bond Returns}

In view of the above data difficulties, we considered using the return on government bonds as a proxy for the return on corporate bonds.

We first tested this proxy with Ibbotson US data because the US capital market has comprehensive historical data sets available. Ibbotson Associates, now owned by Morningstar Corporation, produce comprehensive historical data sets. Their Stocks, Bonds, Bills and Inflation (SBBI) Yearbook provides various types of US financial data. The data sets we selected are long-term corporate bond returns $\left(R_{d}\right)$, long-term government bond returns $\left(R_{r}\right)$, long-term government yields $\left(R_{f}\right)$, and equity returns of large company stocks $\left(R_{m}\right)$. Long-term data sets were chosen instead of intermediate-term sets in order to be consistent with our NZ sample study. The only required data that the SBBI Yearbook does not include is market leverage. Nevertheless, Lally (2002) contains this data. As the sample period of Lally (2002) is from 1952 to 1997, we selected the same sample period for the Ibbotson data.

We start by using the return on US government bonds $\left(R_{r}\right)$ as a proxy for the return on US corporate bonds $\left(R_{d}\right)$. We then calculated the unlevered market return for each US sample year by:

$$
R_{m}^{u}=\frac{R_{m}+R_{r} \frac{B_{m}}{S_{m}}}{1+\frac{B_{m}}{S_{m}}} .
$$

Subtracting $R_{f}$ from $R_{m}^{u}$ for each year over the period 1952 to 1997, and arithmetically averaging the result over the period, gave the estimate of 
the unlevered MRP $\left(M \hat{R} P^{u}\right)$. We used market leverage for year $T$ ( $T=$ $1952,1953, \ldots, 1997)$ to estimate $M R P_{L}$ in the standard CAPM for year $T$ as follows:

$$
M \hat{R} P_{L T}=M \hat{R} P^{u}\left(1+\frac{B_{m T}}{S_{m T}}\right)-\left(\overline{R_{r}-R_{f}}\right) \frac{B_{m T}}{S_{m T}} .
$$

This generated a time series of $M R P_{L}$ estimates over the period 1952-97.

We then repeated these calculations, using the actual value of $R_{d}$ rather than $R_{r}$. This generated another time series of $M R P_{L}$ estimates. The results from using actual $R_{d}$ and from using $R_{r}$ as a proxy for $R_{d}$ are displayed in Figure 3.3.

Figure 3.3: US MRP Estimates from Using $R_{d}$ and from Using $R_{r}$ as a Proxy for $R_{d}$

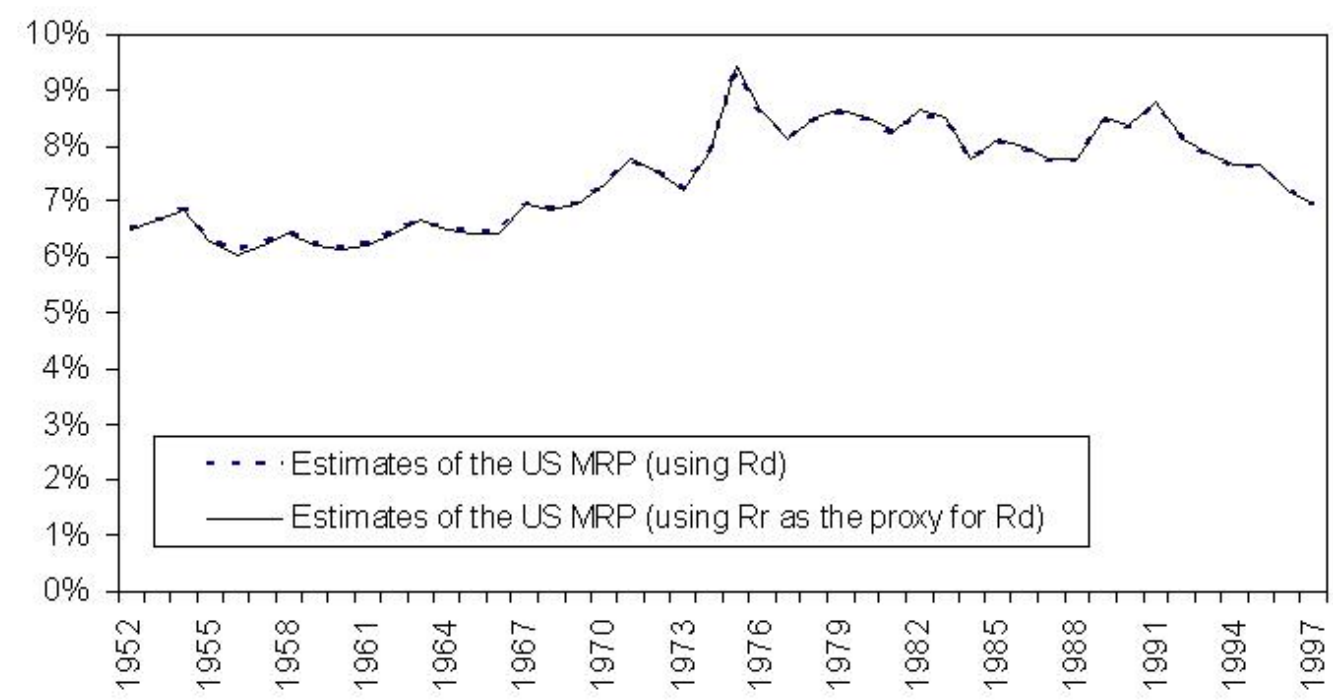

It is extremely hard to distinguish between the two lines. This could be explained by the fact that, although the rate of return on corporate bonds $\left(R_{d}\right)$ and the rate of return on government bonds $\left(R_{r}\right)$ are not identical in any particular year, their averages are very close. Figure 3.4 shows the difference between the return on US corporate bonds and the return on US government bonds from 1952 to 1997. It is clear that $R_{d}$ and $R_{r}$ for the US capital market are different over time. However, the arithmetic means 
Figure 3.4: The Difference between US Corporate Bond Returns and US Government Bond Returns from 1952 to 1997

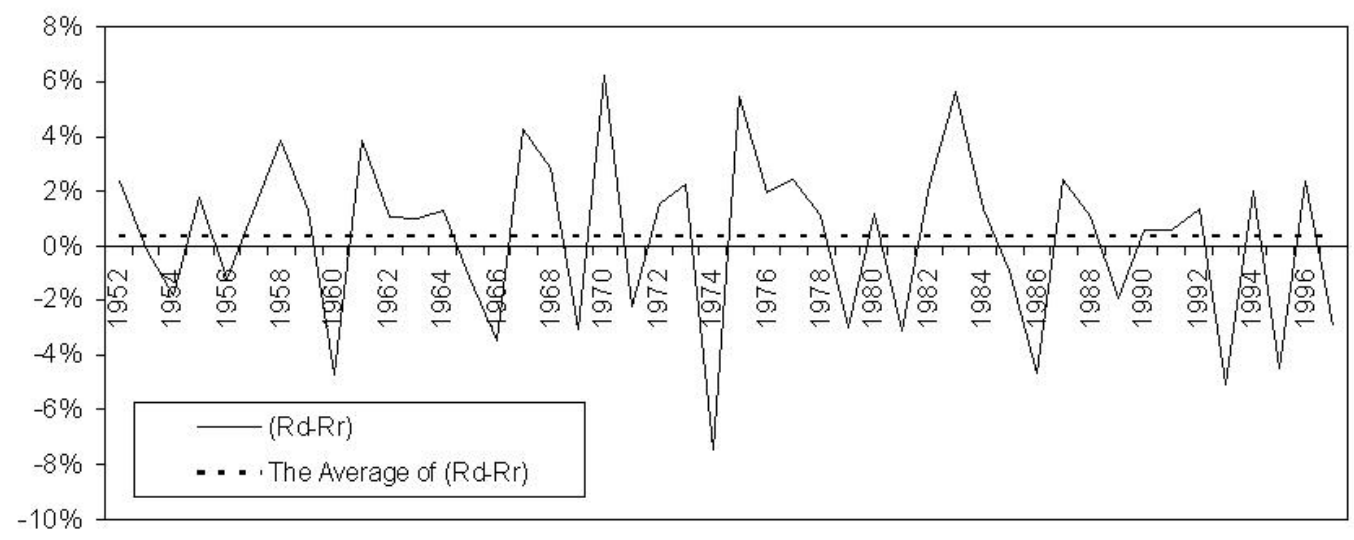

of $R_{d}$ and $R_{r}$ are very close: $6.92 \%$ and $6.59 \%$ respectively. The arithmetic mean of their difference is only $0.33 \%$. Therefore, using the government bond return as a proxy for the corporate bond return makes almost no difference to the Lally estimate of the US MRP in the standard CAPM. This supports our use of the government bond return is a good proxy for the corporate bond return.

We then tested the suitability of using the government bond return as a proxy for the corporate bond return with the NZX Corporate Bond Indices data. The NZX Corporate Bond Indices provide daily index levels over the period 1994-2005. The A Grade Corporate Bond Index was used from 1994 to 2000 and the AB Grade Corporate Bond Index was used from 2001 to 2005. The annual rate of return on corporate bonds was calculated as:

$$
R_{d}=\frac{\text { Index Level at the Beginning of Year } \mathrm{t}+1}{\text { Index Level at the Beginning of Year } \mathrm{t}}-1 \text {. }
$$

Figure 3.5 shows that the rate of return on corporate bonds differs from the rate of return on government bonds over time. Their average difference is $1.04 \%\left(\overline{R_{d}-R_{r}}\right)$. Although this may suggest that $\left(R_{r}+1.04 \%\right)$ is a good proxy for $R_{d}$ in New Zealand, we consider that using $R_{r}$ as a proxy for $R_{d}$ is more appropriate. As the Ibbotson data cover a period of 46 years, 
Figure 3.5: The Difference between NZX Corporate Bond Returns and NZ Government Bond Returns from 1994 to 2005

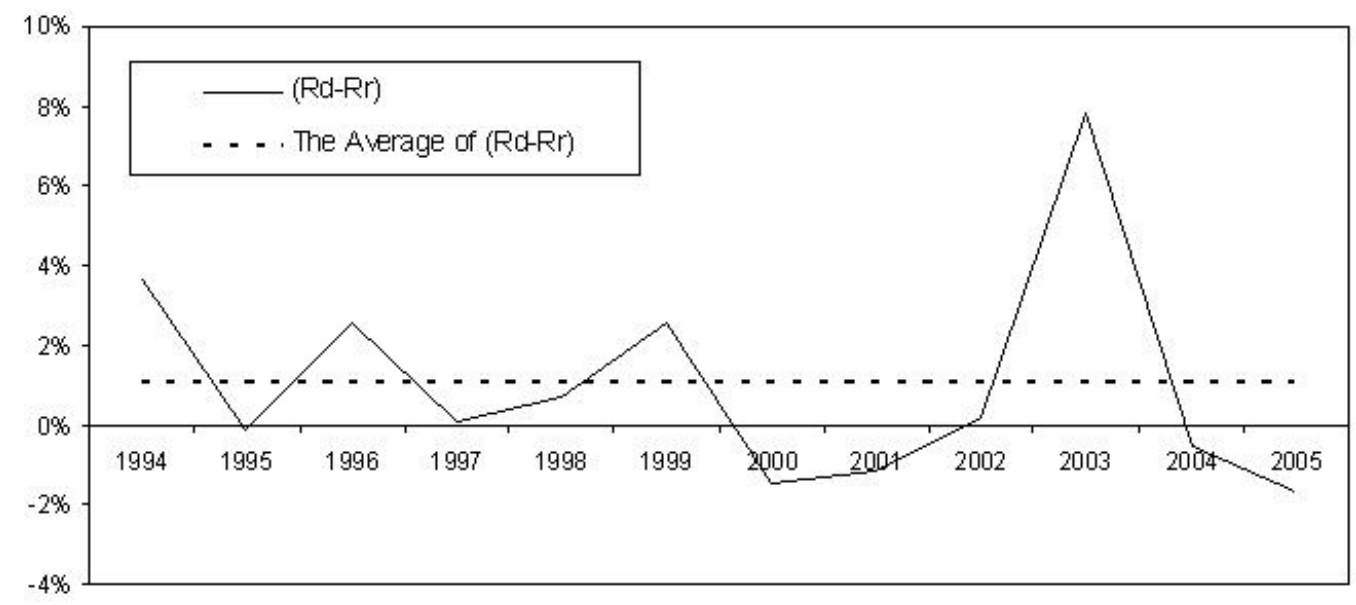

which is 34 years more than the period that the NZX Corporate Bond Indices cover, the Ibbotson US evidence is more reliable than the NZX evidence. Thus, we used the return on 10-year NZ government bonds as a proxy for the return on NZ corporate bonds.

To summarise, by assuming that a Miller (1977) tax world prevails throughout this paper, five data sets, including market returns $\left(R_{m}\right)$, risk free rates of return $\left(R_{f}\right)$, market debt $\left(B_{m}\right)$, market equity $\left(S_{m}\right)$, and the returns on corporate bonds $\left(R_{d}\right)$ were required for the estimation of the MRP under the Lally (2002) method. Only the first two data sets are required under the Ibbotson and Sinquefield (1976) method. The data collection for $R_{m}$ and $R_{f}$ was straight forward, as previous studies had compiled them.

The data sets for $B_{m}$ and $S_{m}$ were manually collected. They form the data set for market leverage $(L)$. Market leverage is estimated as the aggregate debt of companies comprising the market portfolio divided by their aggregate value. The estimation process was conducted every five years over the period 1960-2005. An equity portfolio was used as a proxy for the market portfolio (as usual), and its composition was determined by the equity index that we selected: the RBNZ share price index for 1960-85, 
the NZX 40 index for 1990-2000, and the NZX 50 index for 2005. Companies with large market capitalisation making up $80 \%$ of the total market capitalisation in the equity index were used to proxy for the market portfolio. The individual debt information on these companies was collected from the consolidated balance sheets in their annual reports. The individual equity information was obtained from the Official Record of New Zealand Stock Exchange for 1960-1980, National Business Review for 1985, and the NZX equity indices for 1990-2005. The resulting estimates of market leverage were adjusted, mainly due to time differences between debt and equity valuations, minority interests, and inconsistencies in shares on issue. Other data issues, such as missing data and convertible notes were generally insignificant.

The data set for $R_{d}$ was unavailable, and was therefore proxied by the return on long-term government bonds. The suitability of using this proxy was tested with both the Ibbotson US data and the NZX Corporate Bond Indices data. 


\section{Chapter 4}

\section{Results and Analysis}

This chapter presents the results from applying the Ibbotson and the Lally estimators for the MRP in the standard and the simplified Brennan-Lally versions of the CAPM to New Zealand data over the period 1960-2005. The results are compared and analysed. This chapter also discusses the application of the two estimators in three cases and their implications.

\subsection{Results for the Standard CAPM}

Table B.1 shows the time series of values for $R_{m}, R_{f}, R_{r}, R_{m}^{u}$, and $\frac{B_{m}}{S_{m}}$. Over the period 1960-2005, the average yield on government bonds $\left(\bar{R}_{f}\right)$ was $8.37 \%$. The average return on the market portfolio $\left(\bar{R}_{m}\right)$ was $14.48 \%$. Hence, the Ibbotson estimate of the MRP in the standard CAPM was 6.11\% for 2005, as follows:

$$
\begin{aligned}
M \hat{R} P_{I} & =\bar{R}_{m}-\bar{R}_{f} \\
& =0.1448-0.0837 \\
& =0.0611
\end{aligned}
$$

Using equation 3.3 to determine the unlevered market return $\left(R_{m}^{u}\right)$, the average value was $12.42 \%$. The estimate of the unlevered MRP $\left(M \hat{R} P^{u}\right)$ 
was then $\bar{R}_{m}^{u}-\bar{R}_{f}=4.05 \%$ in the standard CAPM. The average corporate bond return $\left(\bar{R}_{d}\right)$ was proxied by the average government bond return $\left(\bar{R}_{r}\right)$ of $7.61 \%$, and hence the estimate of the debt risk premium $(D \hat{R} P)$ was $\bar{R}_{r}-\bar{R}_{f}=-0.76 \%$. Using the estimated market leverage for 2005 of 0.33 (i.e. $\frac{B_{m T}}{S_{m T}}=0.49$ with $T=2005$ ), the Lally estimate of the MRP in the standard CAPM was $6.40 \%$ for 2005 , as follows:

$$
\begin{aligned}
M \hat{R} P_{L 2005} & =M \hat{R} P^{u}\left(1+\frac{B_{m 2005}}{S_{m 2005}}\right)-D \hat{R} P \frac{B_{m 2005}}{S_{m 2005}} \\
& =0.0405 \times(1+0.49)-(-0.0076) \times 0.49 \\
& =0.0640 .
\end{aligned}
$$

The Ibbotson and Lally MRP estimates were very similar for 2005; they differed by $0.29 \%$. However, when we consider the estimates of market leverage for years prior to 2005, the resulting Lally MRP estimates for some years were significantly different to the Ibbotson MRP estimate. Table 4.1 shows the Ibbotson and the Lally estimates of the MRP in the

Table 4.1: Estimates of the Ibbotson MRP and the Lally MRP in the Standard CAPM

\begin{tabular}{lllll} 
Year & $\frac{B_{m}}{S_{m}}$ & Lally Estimates & Ibbotson Estimates & $\begin{array}{l}\text { Absolute } \\
\text { Difference }\end{array}$ \\
\hline & & & & \\
1960 & 0.3366 & $5.67 \%$ & $6.11 \%$ & $0.44 \%$ \\
1965 & 0.3097 & $5.54 \%$ & $6.11 \%$ & $0.57 \%$ \\
1970 & 0.3069 & $5.52 \%$ & $6.11 \%$ & $0.59 \%$ \\
1975 & 0.8979 & $8.37 \%$ & $6.11 \%$ & $2.26 \%$ \\
1980 & 0.8644 & $8.21 \%$ & $6.11 \%$ & $2.10 \%$ \\
1985 & 0.7349 & $7.58 \%$ & $6.11 \%$ & $1.47 \%$ \\
1990 & 2.983 & $18.40 \%$ & $6.11 \%$ & $12.29 \%$ \\
1995 & 0.5623 & $6.75 \%$ & $6.11 \%$ & $0.64 \%$ \\
2000 & 0.6194 & $7.03 \%$ & $6.11 \%$ & $0.92 \%$ \\
2005 & 0.4881 & $6.40 \%$ & $6.11 \%$ & $0.29 \%$ \\
\hline Mean & 0.8103 & $7.95 \%$ & $6.11 \%$ & $2.16 \%$ \\
\hline
\end{tabular}


standard CAPM over the period 1960-2005. The Lally MRP estimate ranged from $5.52 \%$ (in 1970) to $18.4 \%$ (in 1990), with an average of $7.95 \%$. The Lally estimates of the MRP were similar to the Ibbotson estimate of the MRP at the beginning and the end of the study period. However, the two estimates showed considerable divergence from 1975 to 1990, with 1990 showing the greatest difference of $12.29 \%$.

The Lally MRP was estimated every five years because market leverage was estimated every five years from 1960 to 2005. So, each estimate of the Lally MRP was used to cover a five-year period, from two years before the leverage estimate to two year after it. This results in some dramatic shifts in the estimate (see Figure 4.1).

Figure 4.1: Estimates of the Ibbotson MRP and the Lally MRP in the Standard CAPM

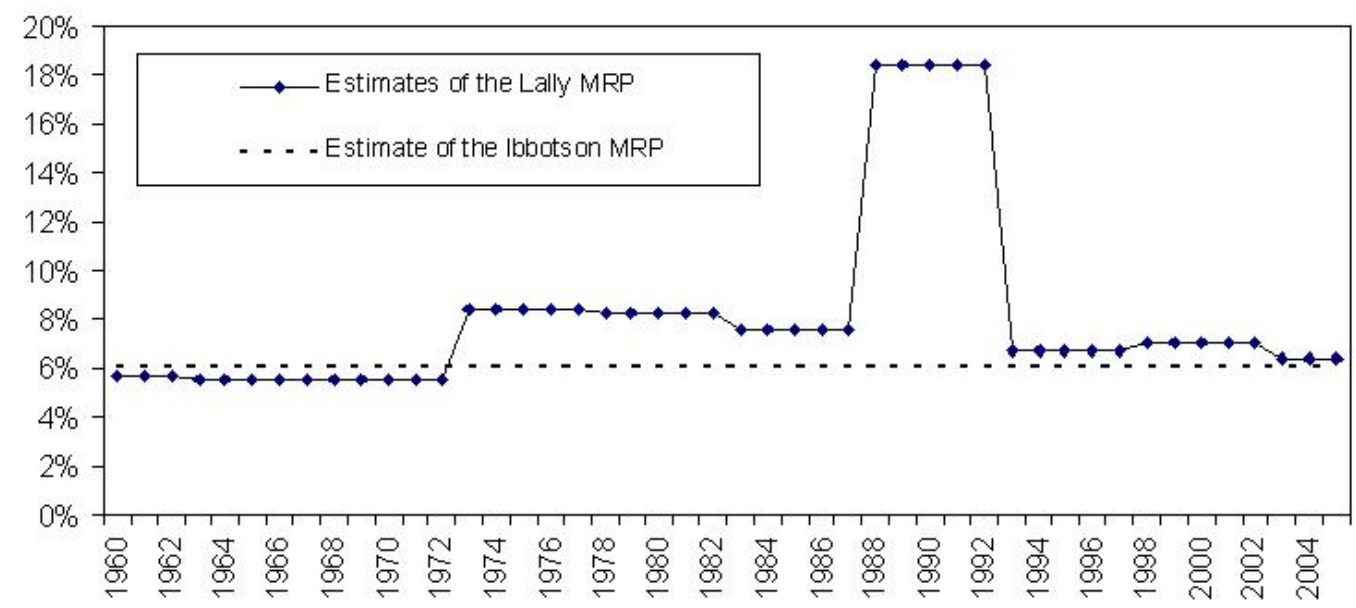

\subsection{Results for the Simplified Brennan-Lally CAPM}

Table B.1 shows the time series of values for $R_{m}, R_{f}, R_{r}, R_{m}^{u}, \frac{B_{m}}{S_{m}}, D_{m}, T_{m}$, and $T_{I}$ along with data required to estimate $T_{m}$ and $T_{I}$ in accordance with 
the equations in section 3.1. The Ibbotson estimator for the MRP in the simplified Brennan-Lally CAPM is:

$$
\begin{aligned}
M \hat{R} P_{I} & =\overline{R_{m}-D_{m} T_{m}-R_{f}\left(1-T_{I}\right)} \\
& =\bar{R}_{m}-\overline{D_{m} T_{m}}-\overline{R_{f}\left(1-T_{I}\right)} .
\end{aligned}
$$

Over the period 1960-2005, the average of $\left(D_{m} T_{m}\right)$ was 0.0056 . The average of $R_{f}\left(1-T_{I}\right)$ was 0.0543 . Hence, the Ibbotson estimate of the MRP in the simplified Brennan-Lally version of the CAPM was $8.49 \%$ for 2005 , as follows:

$$
\begin{aligned}
M \hat{R} P_{I} & =\bar{R}_{m}-\overline{D_{m} T_{m}}-\overline{R_{f}\left(1-T_{I}\right)} \\
& =0.1448-0.0056-0.0543 \\
& =0.0849 .
\end{aligned}
$$

Similarly, the estimate of the unlevered MRP is as follows:

$$
\begin{aligned}
M \hat{R} P^{u} & =\bar{R}_{m}^{u}-\overline{D_{m} T_{m}}-\overline{R_{f}\left(1-T_{I}\right)} \\
& =0.1242-0.0056-0.0543 \\
& =0.0643 .
\end{aligned}
$$

With $\bar{R}_{d}$ being proxied by $\bar{R}_{r}$, the estimate of $D R P$ is:

$$
\begin{aligned}
D \hat{R} P & =\overline{R_{r}}-\overline{D_{m} T_{m}}-\overline{R_{f}\left(1-T_{I}\right)} \\
& =0.0761-0.0056-0.0543 \\
& =0.0162 .
\end{aligned}
$$

Hence, the Lally estimate of the MRP in the simplified Brennan-Lally CAPM was $8.78 \%$ for 2005 , as follows:

$$
\begin{aligned}
M \hat{R} P_{L 2005} & =M \hat{R} P^{u}\left(1+\frac{B_{m 2005}}{S_{m 2005}}\right)-D \hat{R} P \frac{B_{m 2005}}{S_{m 2005}} \\
& =0.0643 \times(1+0.49)-0.0162 \times 0.49 \\
& =0.0878 .
\end{aligned}
$$


Table 4.2: Estimates of the Ibbotson MRP and the Lally MRP in the Simplified Brennan-Lally Version of the CAPM

\begin{tabular}{lllll}
\hline Year & $\frac{B_{m}}{S_{m}}$ & Lally Estimates & Ibbotson Estimates & $\begin{array}{l}\text { Absolute } \\
\text { Difference }\end{array}$ \\
\hline & & & & \\
1960 & 0.3366 & $8.05 \%$ & $8.49 \%$ & $0.44 \%$ \\
1965 & 0.3097 & $7.92 \%$ & $8.49 \%$ & $0.57 \%$ \\
1970 & 0.3069 & $7.91 \%$ & $8.49 \%$ & $0.58 \%$ \\
1975 & 0.8979 & $10.75 \%$ & $8.49 \%$ & $2.26 \%$ \\
1980 & 0.8644 & $10.59 \%$ & $8.49 \%$ & $2.10 \%$ \\
1985 & 0.7349 & $9.97 \%$ & $8.49 \%$ & $1.48 \%$ \\
1990 & 2.983 & $20.79 \%$ & $8.49 \%$ & $12.30 \%$ \\
1995 & 0.5623 & $9.14 \%$ & $8.49 \%$ & $0.65 \%$ \\
2000 & 0.6194 & $9.41 \%$ & $8.49 \%$ & $0.92 \%$ \\
2005 & 0.4881 & $8.78 \%$ & $8.49 \%$ & $0.29 \%$ \\
\hline Mean & 0.8103 & $10.33 \%$ & $8.49 \%$ & $2.16 \%$ \\
\hline
\end{tabular}

Table 4.2 shows the Ibbotson and the Lally estimates of the MRP in the simplified Brennan-Lally version of the CAPM over the period 19602005. The differences between them over time were almost the same as those in the standard CAPM. The Lally MRP estimate ranged from 7.91\% (in 1970) to $20.79 \%$ (in 1990), with an average of $10.33 \%$. Again, the year 1990 showed the greatest difference of $12.30 \%$ between the Ibbotson and the Lally MRP estimates. With each Lally MRP estimate being used to cover a five-year period, the variation in the Lally estimate over time in the simplified Brennan-Lally version of the CAPM is shown in Figure 4.2. 
Figure 4.2: Estimates of the Ibbotson MRP and the Lally MRP in the Simplified Brennan-Lally Version of the CAPM

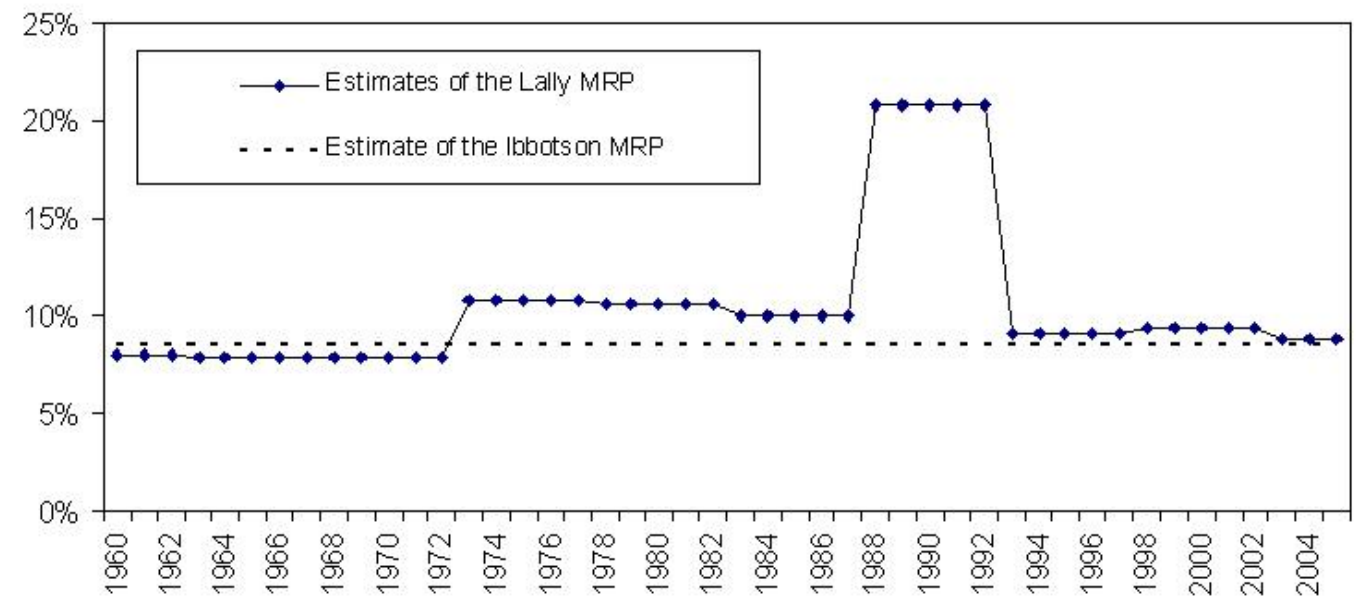

\subsection{Intertemporal Variation in the Lally MRP}

The variation in the Lally MRP over time is due to shifts in market leverage over time, and this in turn to shifts in the values for market capitalisation and market debt. Figure 4.3 shows the variation in the ratio of market debt to market capitalisation from 1960 to 2005. The ratio was low for the

Figure 4.3: Ratio of Market Debt to Market Capitalisation

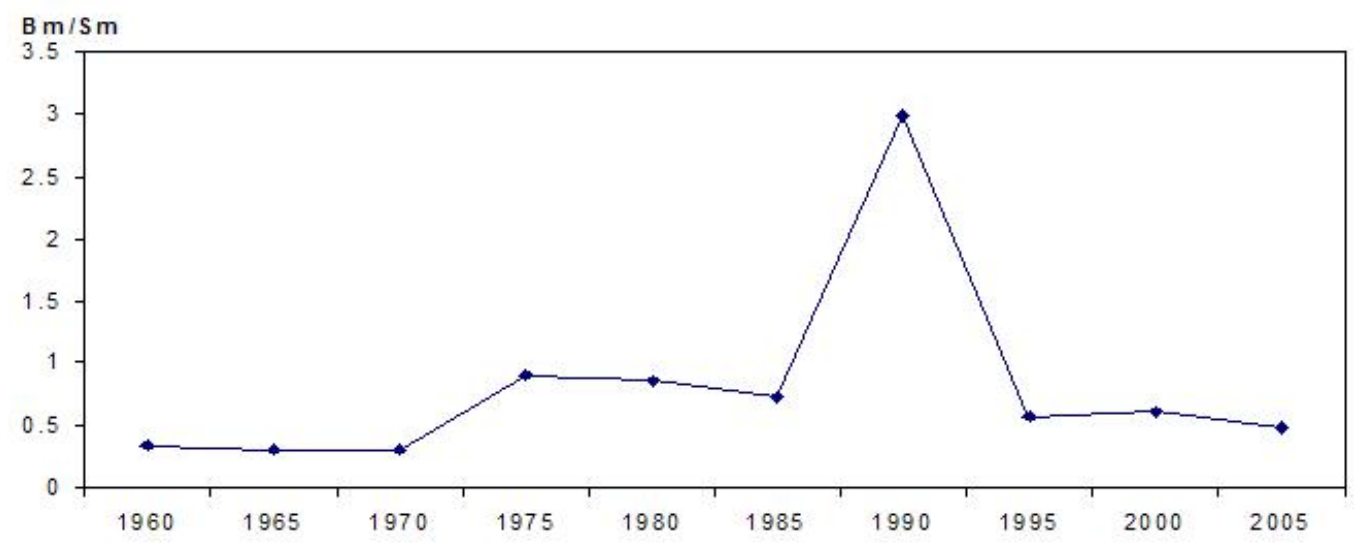

period prior to 1970. It almost tripled in the 1970s and then rose again 
even more dramatically in the late 1980s to its peak, which was almost four times the average ratio over the period 1960-2005. It then declined sharply in the early 1990s, to a point somewhere between the levels for the periods 1960-70 and 1975-85.

Figure 4.4 shows the variation over time in market capitalisation and market debt. Both market capitalisation and market debt rose steadily

Figure 4.4: Market Capitalisation and Market Debt

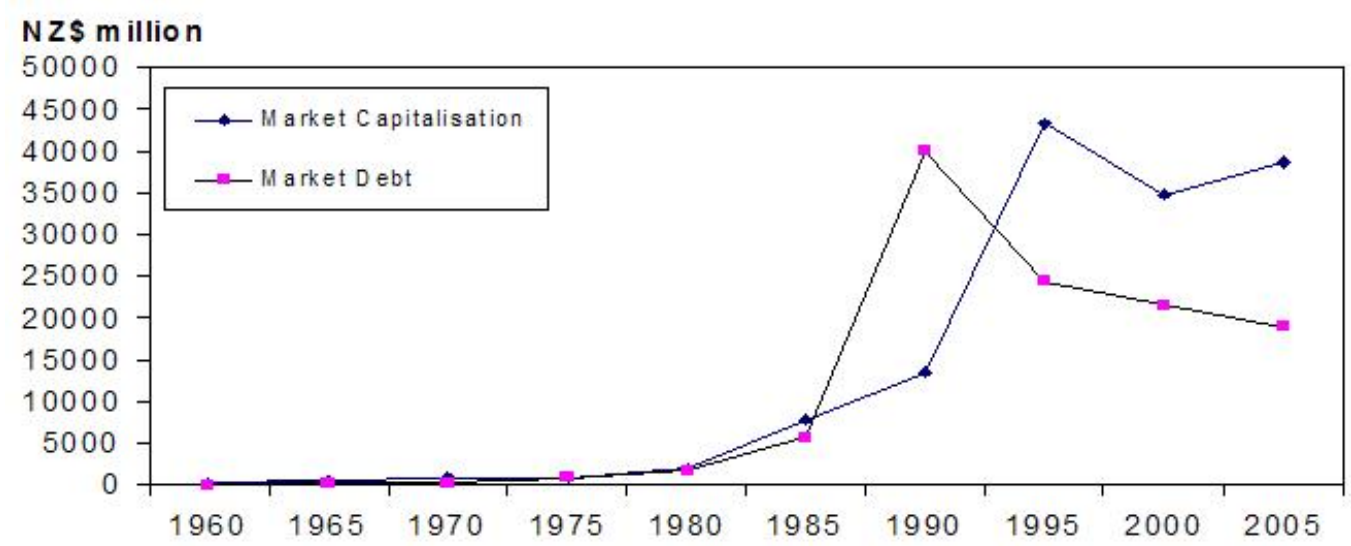

from 1975. In 1990, market debt reached to its peak, which was about three times market capitalisation. After 1990, market debt dropped dramatically and was below market capitalisation from 1995. In contrast, market capitalisation reached its peak in 1995, and has essentially remained at that level since.

The spike in leverage in 1990 is therefore due to a spike in debt, for which a possible explanation is an increase up to the 1987 stock market crash, which was only slowly reversed. Compounding this downtrend would be the dividend imputation system introduced in 1988, which effectively removed the tax advantage of debt. 


\subsection{Further Results}

It may be argued that the time series of estimates for the Lally MRP prior to 2005 are unrealistic, as we estimated the unlevered MRP by using data over the entire 1960-2005 period. To investigate the Lally MRP estimator in a more realistic context, we considered three situations: estimating the MRP in the standard CAPM for 1985, 1990, and 2000. In each case, we only used historical data up to that year for estimating the MRP. The results are shown in Table 4.3.

In case I, we estimated both the Ibbotson and the Lally MRP for 1985 (shortly before the 1987 stock market crash). Using data from 1960-85, the Ibbotson MRP was estimated at $9.50 \%$ and the Lally MRP was estimated at $10.23 \%$ for 1985 . They differed by $0.73 \%$.

In case II, we estimated the MRP for 1990 (shortly after the stock market crash). Using data over the period 1960-90, the Ibbotson MRP was estimated at $6.45 \%$ and the Lally MRP was estimated at $21.66 \%$. While the Ibbotson MRP estimate does not reflect the high volatility of the market at that time (arising from high leverage), the Lally MRP estimator explicitly takes this into account and this leads to the much higher estimate of the MRP.

In case III, we estimated the MRP for 2000, after the market recovered from the 1987 stock market crash. Using data from 1960-2000, the Ibbotson MRP estimate was 5.81\%, and the Lally MRP estimate was 6.75\%. Again, the Ibbotson and the Lally MRP estimates were very similar, with a difference of $0.94 \%$.

Therefore, under most conditions, the estimates from the two methods are similar and only diverge significantly when market leverage is unusually high or low (as it was in 1990). 


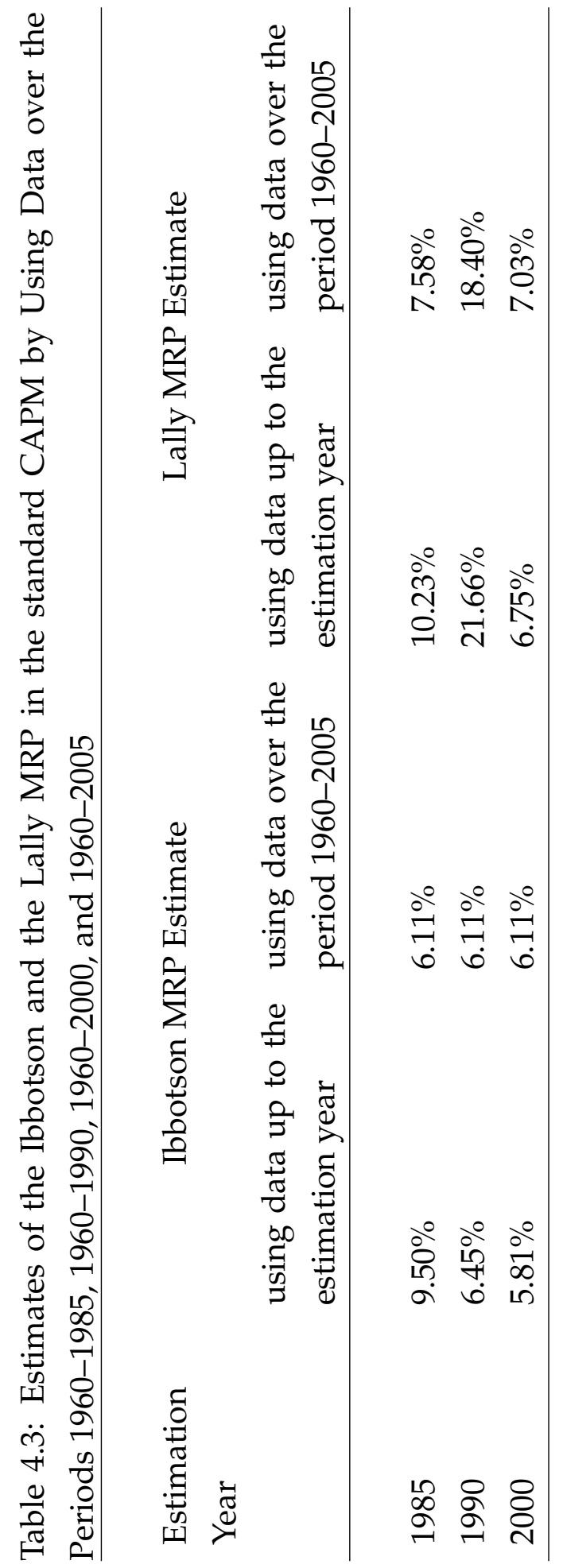

64 


\section{Chapter 5}

\section{Conclusion}

This paper applied two methods to estimate the MRP in both the standard and the simplified Brennan-Lally versions of the CAPM to New Zealand data over the period 1960-2005. The first is the Lally (2002) method. It is derived from Modigliani and Miller $(1958,1963)$ proposition II, which relates a company's cost of equity to its leverage. When using an equity portfolio as a proxy for the market portfolio, which is general practice, "market" leverage should therefore affect the expected return on the "market" portfolio and consequently the MRP. The Lally method first estimates the unlevered MRP by averaging excess unlevered returns and then adjusts it for market leverage to generate an estimate of the levered MRP. The resulting MRP estimate varies over time with market leverage. The second method is the Ibbotson and Sinquefield (1976) method. This simply averages the annual excess return over a long period and hence directly estimates the levered MRP. The results from applying the Lally method are compared to those from the Ibbotson method, due to the similarity in the two methodologies. Both arithmetically average historical data, and they will generate the same result if market leverage does not change over time

In respect of the standard CAPM, the resulting Ibbotson MRP estimate was $6.11 \%$ and the Lally estimate was $6.40 \%$ for 2005 . In respect of the sim- 
plified Brennan-Lally version of the CAPM, the estimates were $8.49 \%$ and $8.78 \%$ respectively. By using estimates of market leverage for years prior to 2005 , the resulting Lally MRP estimates ranged from $5.52 \%$ to $18.40 \%$ in the standard CAPM and from $7.91 \%$ to $20.79 \%$ in the simplified BrennanLally version. The year 1990 gave rise to an extremely large estimate for the MRP in both versions of the CAPM using the Lally method, due to the very high level of market leverage, which in turn was caused by a spike in debt. We also estimated the MRPs for 1985, 1990, and 2000 in the standard CAPM by only using historical data up to each year. Again, the estimate for 1990 using the Lally methodology was very high. In general, the Ibbotson and Lally estimators produced similar results except when market leverage was very high or low.

The Lally estimator is superior to the Ibbotson estimator because it better reflects changes in market leverage. In addition, and relative to the Merton method, because the Lally MRP estimator is theoretically based rather than empirically developed, it is not exposed to unrepresentative statistical data. However, the Lally MRP estimator may be exposed to the risk of model error. Furthermore, as the Lally MRP estimator presumes the use of an equity portfolio as the proxy for the market portfolio, the method will be irrelevant if the market portfolio contains both equity and debt at market values. 


\section{Appendix A}

\section{Estimation of the Market Value of Debt}

Previous studies, such as Hirschey (1985) and Fama and French (1999), use the book value of debt as a proxy for its market value because it is difficult to obtain historical data on the market value of debt. If the interest rate on debt is generally stable over time, the market value of debt will be generally very close to its book (face) value. Therefore, the book value of debt is generally a good proxy for its market value. However, the market value of debt may diverge from its book value when market conditions change rapidly. The following analysis aims to assess the magnitude of this divergence. It also discusses the implications for the MRP estimate.

There are two main reasons for a potential divergence between the market value of debt and its book value: a change in the level of inflation and a change in the level of default risk. Both will lead to a different required rate of return on debt. Floating interest rates, such as those on bank overdrafts and some subordinate notes, are affected by changes in the inflation rate and default risk. Hence, the market value of such debt will remain close to the book value. However, most corporate debt has fixed coupon interest rates, including corporate bonds, term loans, and mortgages. Their rates are determined at the time of issue, and therefore 
do not reflect changes in inflation or default risk. As debt with fixed interest rates is generally the major part of a company's debt, rapid changes in market interest rates could cause a divergence between the book value and the market value of a company's debt.

The market portfolio in 1990 was chosen for examination as the period it covers in this paper (1988-92) involved significant changes in both inflation and default risk. Figure A.1 shows that the inflation rate was unstable, especially in the period 1984-92. The inflation rate reached its peak

Figure A.1: Fourth-Quarter-Ended Inflation Rates from 1960 to 2005

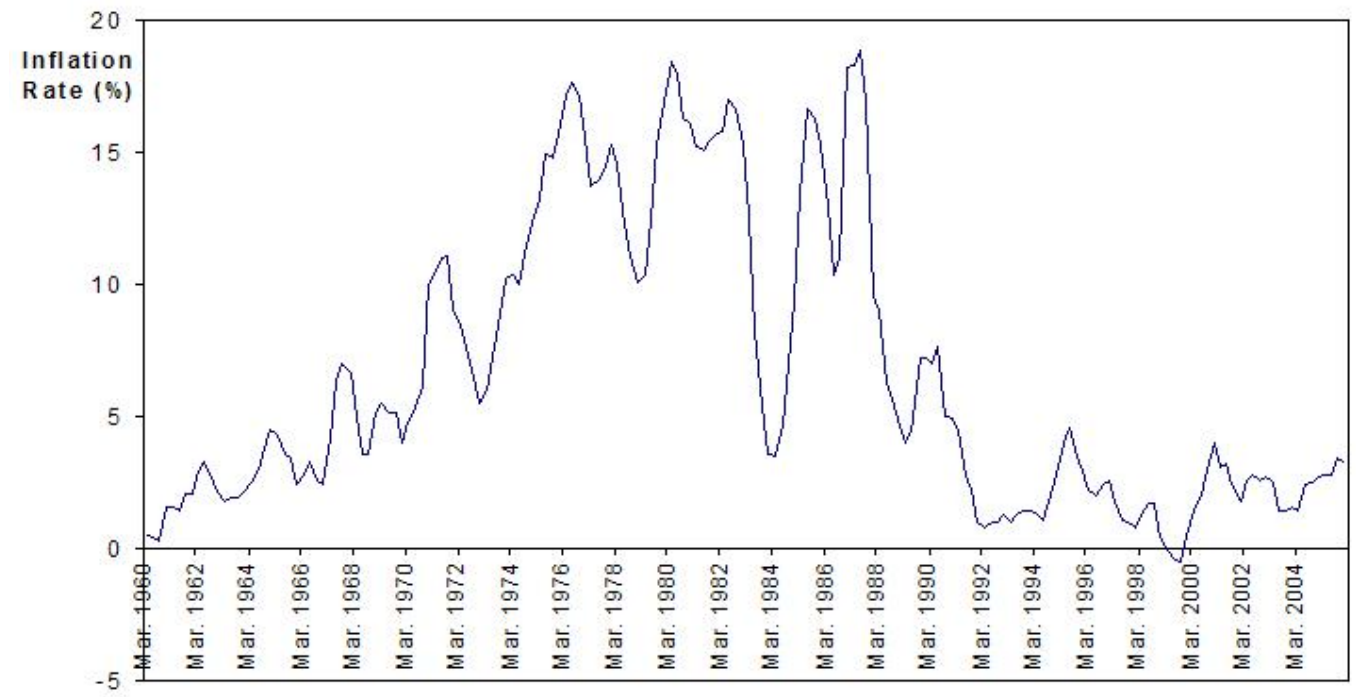

Source: Statistics NZ

of $18.9 \%$ in 1987 and dropped rapidly to $0.8 \%$ in 1992 . Figure A.2 shows that the government bond yield was very high in 1987 at $18.86 \%$ and decreased to $6.14 \%$ in 1992 . The nominal rate of return on government bonds fell so that real rates of return were roughly constant.

Taking only the decreased level of inflation into account, the nominal yield on corporate bonds should have dropped in accordance with that on government bonds. That is, the market interest rate on corporate bonds 
Figure A.2: Monthly Average Yield on One-Year Secondary Market Government Bonds over the Period 1987 to 2005

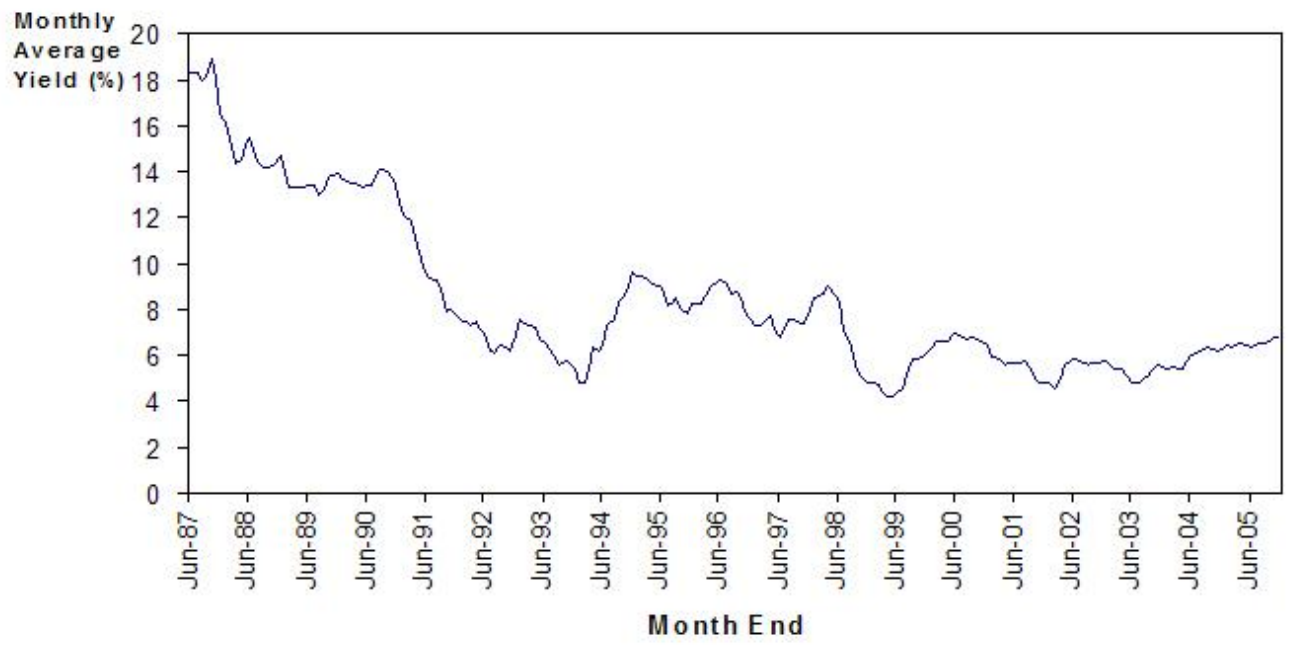

Notes: Pre-1987 yield data of one-year secondary market government bonds are unavailable.

in 1990 should be lower than the coupon rate on fixed rate corporate debt issued prior to 1990. Consequently, corporate debt issued prior to 1990 should have a market value in 1990 higher than its book value.

Default risk is likely to have sharply increased after the stock market crash in 1987, when many NZ companies went bankrupt. The increased market interest rate should reduce the market value of fixed rate corporate debt that was issued prior to 1990. Hence, corporate debt should have had a market value in 1990 lower than its book value if we account for the increased level of default risk.

To determine the market value of debt with fixed interest rates, we require data on three parameters: the coupon rate of debt (which was determined before 1990), the maturity date, and the market interest rate in 1990. Assuming that coupons were paid half-yearly, the market value of 
debt is as follows:

$$
M V=\frac{\frac{C}{2}}{(1+Y)^{\frac{m}{12}}}+\frac{\frac{C}{2}}{(1+Y)^{\frac{m+6}{12}}}+\cdots+\frac{\frac{C}{2}}{(Y+1)^{\frac{n-6}{12}}}+\frac{\frac{C}{2}+B V}{(1+Y)^{\frac{n}{12}}}
$$

where $C$ is the annual coupon payment $(C=B V \times r$, where $r$ is the coupon interest rate of debt); $B V$ is the book value of debt; $M V$ is the market value of debt; $Y$ is the market interest rate for corporate debt in 1990; $m$ is the number of months left from the balance date of a company's annual report to the date of the next coupon payment; $n$ is the number of months left from the balance date to the maturity date.

Although the formula for the market value of debt is straightforward, we do not know the market interest rate for corporate debt in $1990(Y)$. In section 3.3.5, we used the rate of return on government bonds as a proxy for the return on corporate bonds, and showed that it was a good approximation using Ibbotson US data over the period 1952-97. However, since the New Zealand market experienced much higher default risk in 1990, the yield on corporate bonds is likely to have significantly exceeded the yield on government bonds. Hence, we approximated the value for $Y$ by adding a debt premium to the government bond yield. The government bond yield we used for the calculation is the monthly average one-year secondary market government bond yield (in figure A.2). The month it refers to must be the same as on the balance sheet. The 2006 New Zealand Company Beta Book shows that the debt premiums for $37 \mathrm{New}$ Zealand listed companies relative to the three-year government bond yield were within a range of $1.08 \%-2.20 \%$. Thus, we set the yield on government bonds $\left(R_{f}\right)$ plus $1 \%$ to be the lower bound for the yield on corporate bonds. The resulting market value from using $\left(R_{f}+1 \%\right)$ as the proxy for the interest rate of corporate debt in 1990 gives rise to the upper bound on the potential market value of corporate debt. As the range of the debt premiums in the 2006 New Zealand Company Beta Book were obtained when market leverage was relatively low, we used an upper bound of $4 \%$ for the debt premium, in consideration of the extremely large market leverage ra- 
tio (and hence default risk) in 1990. Thus, by applying debt premiums of $1 \%$ and $4 \%$ to the government bond yield in 1990, we obtained upper and lower bounds on the market values of corporate debt with fixed interest rates.

Another problem we encountered was that six out of 23 companies that comprise the 1990 market portfolio do not provide any information on the coupon interest rate and the maturity date of debt. The remaining 17 companies provide a range of coupon interest rates and/or a range of maturity dates. We averaged the coupon interest rates and/or maturity dates of debt for these companies. As a result, we were able to estimate the market value of debt for 17 companies in the 1990 market portfolio.

Table A.1 shows the results. Fletcher Challenge Ltd shows the greatest divergence between the market value of debt and its book value. If the debt premium is $4 \%$, the market value is less than the book value by $15.1 \%$.

Although we were unable to estimate the market value of debt for six companies, we could approximate them by treating the other 17 companies as representative. For these 17 companies, we calculated their aggregate book value and market values under two debt premiums (1\% and $4 \%$ ). We divided each aggregate market value by the aggregate book value, which gave us two market to book ratios corresponding to debt premiums of $1 \%$ and $4 \%: 98.2 \%$ and $95.5 \%$ respectively. Applying these ratios to the book value of debt for the other six companies gave an approximation of their market values. Table A.2 shows the book value and market value of each company's total debt (those with fixed interest rates and floating interest rates). It also displays the resulting market leverage ratios and the MRP estimates.

Table A. 2 shows that the estimated MRP is hardly affected by the use of book or market value for debt or the estimate for the debt risk premium. If the book value is used as a proxy for the market value of debt, the estimate of the MRP in 1990 is $18.26 \%$. If market value is used with a debt risk premium of $1 \%$, the MRP estimate drops by only $0.28 \%$. If the market 
value is used with a debt risk premium of $4 \%$, the MRP estimate drops by only a further $0.41 \%$. Therefore, approximating the market value of debt by its book value would seem to be satisfactory for the purposes of this study. 
Table A.1: Comparison between the Book Value and the Market Value of Debt with Fixed Interest Rates in the 1990 Market Portfolio

\begin{tabular}{|c|c|c|c|}
\hline \multirow[t]{2}{*}{ Companies } & \multirow{2}{*}{$\begin{array}{l}\text { Book values } \\
\text { of debt with } \\
\text { fixed interest } \\
\text { rates } \\
\text { (in } \$ \mathrm{~m} \text { ) }\end{array}$} & \multicolumn{2}{|c|}{$\begin{array}{l}\text { Estimated market values (as a } \\
\text { proportion of book values) by using } \\
\text { the following discount rates: }\end{array}$} \\
\hline & & $\begin{array}{l}\mathrm{Rf}+1 \% \\
\text { (in } \$ \mathrm{~m})\end{array}$ & $\begin{array}{l}\mathrm{Rf}+4 \% \\
\text { (in } \$ \mathrm{~m})\end{array}$ \\
\hline Fletcher Challenge Ltd & 7,867 & $7,239(92.02 \%)$ & $6,679(84.90 \%)$ \\
\hline BIL International Ltd & 2,890 & $2,942(101.8 \%)$ & $2,770(95.84 \%)$ \\
\hline Carter Holt Harvey Ltd & 2,193 & $2,094(95.47 \%)$ & $1,930(87.99 \%)$ \\
\hline Lion Nathan Ltd & 605.8 & $627.0(103.5 \%)$ & $598.2(98.74 \%)$ \\
\hline Bank of New Zealand & 908.3 & $910.2(100.2 \%)$ & $885.2(97.46 \%)$ \\
\hline Wilson\&Horton Ltd & 43.68 & $45.68(104.6 \%)$ & $43.23(98.96 \%)$ \\
\hline Independent Newspapers Ltd & 160.6 & $158.0(98.38 \%)$ & $147.8(92.01 \%)$ \\
\hline Air New Zealand ltd & 446.7 & $425.9(95.34 \%)$ & $398.9(89.29 \%)$ \\
\hline $\begin{array}{l}\text { Fisher\&Paykel Healthcare Corp. } \\
\text { Ltd. }\end{array}$ & 110.7 & $106.4(96.15 \%)$ & $98.86(89.32 \%)$ \\
\hline Fay Richwhite \& Company Ltd & 238.4 & $239.0(100.2 \%)$ & $230.2(96.55 \%)$ \\
\hline The NZ Refining Company Ltd & & \multicolumn{2}{|c|}{ Insufficient Information } \\
\hline Wilson Neil Ltd & & \multicolumn{2}{|c|}{ Insufficient Information } \\
\hline BNZ Finance & 822.9 & $817.3(99.33 \%)$ & $796.5(96.79 \%)$ \\
\hline Sanford ltd & 34.87 & $33.39(95.75 \%)$ & $31.08(89.11 \%)$ \\
\hline Countrywide & & \multicolumn{2}{|c|}{ Insufficient Information } \\
\hline Fortex Group Ltd & 35.48 & $34.91(98.40 \%)$ & $32.54(91.72 \%)$ \\
\hline Asian Properties Ltd & 78.02 & $71.26(91.34 \%)$ & $66.81(85.62 \%)$ \\
\hline Jarden Morgan Ltd & & \multicolumn{2}{|c|}{ Insufficient Information } \\
\hline Shortland Properties Ltd & 15.00 & $15.06(100.42 \%)$ & $14.1(93.99 \%)$ \\
\hline Steel\&Tube Holdings Ltd & & \multicolumn{2}{|c|}{ Insufficient Information } \\
\hline Donaghys Ltd & 26.61 & $27.10(101.8 \%)$ & $25.63(96.32 \%)$ \\
\hline Milburn NZ Ltd & 62.57 & $63.57(101.6 \%)$ & $59.60(95.26 \%)$ \\
\hline Waste Management NZ Ltd & & \multicolumn{2}{|c|}{ Insufficient Information } \\
\hline
\end{tabular}

Notes: $R_{f}$ is the monthly average of the one-year secondary market government bond yield in 1990 . 
Table A.2: The Book and Market Values of Aggregate Debt, Market Leverage, and MRP Estimates in the 1990 Market Portfolio

\begin{tabular}{|c|c|c|c|c|}
\hline \multirow[t]{2}{*}{ Companies } & \multirow{2}{*}{$\begin{array}{l}\text { Market Value } \\
\text { of equity } \\
\text { (in\$m) }\end{array}$} & \multirow{2}{*}{$\begin{array}{l}\text { Book value } \\
\text { of debt } \\
\text { (in } \$ \mathrm{~m} \text { ) }\end{array}$} & \multicolumn{2}{|c|}{$\begin{array}{l}\text { Market value of debt when } \\
\text { the discount rate equals: }\end{array}$} \\
\hline & & & $\begin{array}{l}\mathrm{Rf}+1 \% \\
(\mathrm{in} \$ \mathrm{~m})\end{array}$ & $\begin{array}{l}\mathrm{Rf}+4 \% \\
\text { (in } \$ \mathrm{~m})\end{array}$ \\
\hline Fletcher Challenge Ltd & 3,986 & 8,527 & 7,899 & 7,339 \\
\hline BIL International Ltd & 1,901 & 4,723 & 4,775 & 4,603 \\
\hline Carter Holt Harvey Ltd & 1,666 & 4,190 & 4,090 & 3,926 \\
\hline Lion Nathan Ltd & 1,065 & 795.3 & 816.4 & 787.6 \\
\hline Bank of New Zealand & 600.6 & 17,773 & 17,775 & 17,750 \\
\hline Wilson\&Horton Ltd & 398.0 & 56.75 & 58.75 & 56.30 \\
\hline Independent Newspapers Ltd & 359.9 & 158.3 & 155.9 & 146.5 \\
\hline Air New Zealand Ltd & 187.5 & 381.3 & 367.8 & 350.2 \\
\hline $\begin{array}{l}\text { Fisher \& Paykel Healthcare } \\
\text { Corp. Ltd }\end{array}$ & 171.3 & 126.9 & 122.6 & 115.0 \\
\hline Fay Richwhite \& Company Ltd & 156.7 & 342.4 & 342.9 & 334.1 \\
\hline The NZ Refining Company Ltd & 145.2 & 0.801 & 0.787 & 0.765 \\
\hline Wilson Neil Ltd & 131.5 & 188.3 & 184.9 & 179.8 \\
\hline BNZ Finance & 128.7 & 824.5 & 819.0 & 798.1 \\
\hline Sanford ltd & 123.8 & 41.57 & 40.09 & 37.77 \\
\hline Countrywide & 110.1 & 1,522 & 1,495 & 1,454 \\
\hline Fortex Group Ltd & 85.00 & 58.78 & 58.21 & 55.84 \\
\hline Asian Properties Ltd & 74.76 & 78.49 & 71.73 & 67.28 \\
\hline Jarden Morgan Ltd & 64.58 & 9.670 & 9.497 & 9.236 \\
\hline Shortland Properties Ltd & 56.88 & 17.35 & 17.41 & 16.45 \\
\hline Steel\&Tube Holdings Ltd & 52.11 & 49.66 & 48.77 & 47.43 \\
\hline Donaghys Ltd & 51.57 & 32.96 & 33.45 & 31.98 \\
\hline Milburn NZ Ltd & 50.01 & 69.70 & 70.69 & 66.73 \\
\hline Waste Management NZ Ltd & 41.95 & 9.697 & 9.524 & 9.262 \\
\hline Aggregate Value & 11,667 & 39,976 & 39,262 & 38,182 \\
\hline Market Leverage & & $77.41 \%$ & $77.09 \%$ & $76.59 \%$ \\
\hline $\begin{array}{l}\text { Market Leverage (adjusted for the } \\
\text { effect of minority interests) }\end{array}$ & & $74.71 \%$ & $74.37 \%$ & $73.84 \%$ \\
\hline Resulting Estimate of the MRP & & $18.26 \%$ & $17.98 \%$ & $17.57 \%$ \\
\hline
\end{tabular}




\section{Appendix B}

\section{Summary of Data}

Table B.1: Total Data Sets for this Paper

\begin{tabular}{|c|c|c|c|c|c|c|c|c|c|c|c|c|}
\hline $\begin{array}{l}\text { End } \\
\text { Year }\end{array}$ & $R_{m}$ & $R_{f}$ & $R_{r}$ & $\frac{B_{m}}{S_{m}}$ & $R_{m}^{u}$ & $D_{m}$ & $w_{A}$ & $T_{0}$ & $p$ & $T_{c}$ & $T_{m}$ & $T_{I}$ \\
\hline 1960 & 0.151 & 0.048 & 0.042 & 0.337 & 0.123 & 0.041 & 0.810 & 0.387 & 0.42 & & 0.132 & 0.313 \\
\hline 1961 & -0.060 & 0.051 & 0.016 & 0.337 & -0.041 & 0.047 & 0.810 & 0.387 & 0.42 & & 0.132 & 0.313 \\
\hline 1962 & 0.128 & 0.053 & 0.060 & 0.337 & 0.111 & 0.050 & 0.810 & 0.387 & 0.42 & & 0.132 & 0.313 \\
\hline 1963 & 0.252 & 0.052 & 0.058 & 0.310 & 0.206 & 0.047 & 0.810 & 0.400 & 0.42 & & 0.136 & 0.324 \\
\hline 1964 & 0.146 & 0.051 & 0.057 & 0.310 & 0.125 & 0.044 & 0.810 & 0.412 & 0.42 & & 0.140 & 0.334 \\
\hline 1965 & -0.059 & 0.051 & 0.044 & 0.310 & -0.035 & 0.046 & 0.810 & 0.412 & 0.42 & & 0.140 & 0.334 \\
\hline 1966 & 0.008 & 0.053 & 0.034 & 0.310 & 0.014 & 0.051 & 0.810 & 0.412 & 0.42 & & 0.140 & 0.334 \\
\hline 1967 & -0.049 & 0.055 & 0.041 & 0.310 & -0.028 & 0.059 & 0.810 & 0.425 & 0.42 & & 0.145 & 0.344 \\
\hline 1968 & 0.482 & 0.055 & 0.056 & 0.307 & 0.382 & 0.052 & 0.810 & 0.437 & 0.42 & & 0.149 & 0.354 \\
\hline 1969 & 0.211 & 0.055 & 0.056 & 0.307 & 0.174 & 0.044 & 0.810 & 0.490 & 0.42 & & 0.167 & 0.397 \\
\hline 1970 & -0.051 & 0.055 & 0.058 & 0.307 & -0.025 & 0.047 & 0.810 & 0.620 & 0.42 & & 0.211 & 0.502 \\
\hline 1971 & 0.003 & 0.055 & 0.052 & 0.307 & 0.015 & 0.055 & 0.810 & 0.475 & 0.42 & & 0.162 & 0.385 \\
\hline 1972 & 0.245 & 0.055 & 0.055 & 0.307 & 0.020 & 0.051 & 0.810 & 0.435 & 0.42 & & 0.148 & 0.352 \\
\hline 1973 & 0.003 & 0.058 & 0.016 & 0.898 & 0.009 & 0.049 & 0.810 & 0.423 & 0.42 & & 0.144 & 0.343 \\
\hline 1974 & -0.178 & 0.061 & 0.058 & 0.898 & -0.066 & 0.071 & 0.810 & 0.450 & 0.42 & & 0.153 & 0.365 \\
\hline 1975 & 0.218 & 0.063 & 0.022 & 0.898 & 0.125 & 0.077 & 0.810 & 0.480 & 0.42 & & 0.163 & 0.389 \\
\hline
\end{tabular}


Table B.1 (continued)

\begin{tabular}{|c|c|c|c|c|c|c|c|c|c|c|c|c|}
\hline $\begin{array}{l}\text { End } \\
\text { Year }\end{array}$ & $R_{m}$ & $R_{f}$ & $R_{r}$ & $\frac{B_{m}}{S_{m}}$ & $R_{m}^{u}$ & $D_{m}$ & $w_{A}$ & $T_{0}$ & $p$ & $T_{c}$ & $T_{m}$ & $T_{I}$ \\
\hline 1976 & 0.101 & 0.083 & -0.062 & 0.898 & 0.024 & 0.072 & 0.810 & 0.483 & 0.42 & & 0.164 & 0.391 \\
\hline 1977 & -0.073 & 0.093 & 0.014 & 0.898 & -0.032 & 0.085 & 0.810 & 0.486 & 0.40 & & 0.158 & 0.394 \\
\hline 1978 & 0.212 & 0.100 & 0.099 & 0.864 & 0.160 & 0.085 & 0.810 & 0.473 & 0.44 & & 0.169 & 0.383 \\
\hline 1979 & 0.226 & 0.120 & -0.055 & 0.864 & 0.096 & 0.090 & 0.810 & 0.480 & 0.43 & & 0.167 & 0.389 \\
\hline 1980 & 0.578 & 0.133 & 0.132 & 0.864 & 0.371 & 0.080 & 0.810 & 0.480 & 0.30 & & 0.117 & 0.389 \\
\hline 1981 & 0.341 & 0.128 & 0.156 & 0.864 & 0.255 & 0.058 & 0.810 & 0.550 & 0.36 & & 0.160 & 0.446 \\
\hline 1982 & -0.079 & 0.129 & 0.112 & 0.864 & 0.009 & 0.077 & 0.810 & 0.310 & 0.24 & & 0.060 & 0.251 \\
\hline 1983 & 1.194 & 0.122 & 0.271 & 0.735 & 0.803 & 0.087 & 0.810 & 0.312 & 0.31 & & 0.078 & 0.253 \\
\hline 1984 & 0.264 & 0.126 & -0.192 & 0.735 & 0.071 & 0.056 & 0.810 & 0.320 & 0.21 & & 0.054 & 0.259 \\
\hline 1985 & 0.337 & 0.177 & 0.177 & 0.735 & 0.269 & 0.047 & 0.810 & 0.451 & 0.66 & & 0.241 & 0.365 \\
\hline 1986 & 1.014 & 0.164 & 0.168 & 0.735 & 0.655 & 0.031 & 0.810 & 0.520 & 1.00 & & 0.421 & 0.421 \\
\hline 1987 & -0.486 & 0.157 & 0.239 & 0.735 & -0.179 & 0.033 & 0.810 & 0.480 & 1.00 & & 0.389 & 0.389 \\
\hline 1988 & -0.080 & 0.131 & 0.177 & 2.983 & 0.113 & 0.041 & & 0.400 & & 0.28 & 0.167 & 0.400 \\
\hline 1989 & 0.159 & 0.128 & 0.159 & 2.983 & 0.159 & 0.048 & & 0.330 & & 0.33 & 0 & 0.330 \\
\hline 1990 & -0.371 & 0.125 & 0.144 & 2.983 & 0.015 & 0.047 & & 0.330 & & 0.33 & 0 & 0.330 \\
\hline 1991 & 0.283 & 0.101 & 0.204 & 2.983 & 0.224 & 0.047 & & 0.330 & & 0.33 & 0 & 0.330 \\
\hline 1992 & 0.115 & 0.084 & 0.120 & 2.983 & 0.119 & 0.044 & & 0.330 & & 0.33 & 0 & 0.330 \\
\hline 1993 & 0.494 & 0.068 & 0.135 & 0.562 & 0.365 & 0.040 & & 0.330 & & 0.33 & 0 & 0.330 \\
\hline 1994 & -0.084 & 0.078 & -0.028 & 0.562 & -0.064 & 0.041 & & 0.330 & & 0.33 & 0 & 0.330 \\
\hline 1995 & 0.173 & 0.079 & 0.132 & 0.562 & 0.159 & 0.050 & & 0.330 & & 0.33 & 0 & 0.330 \\
\hline 1996 & 0.164 & 0.081 & 0.086 & 0.562 & 0.136 & 0.049 & & 0.330 & & 0.33 & 0 & 0.330 \\
\hline 1997 & 0.011 & 0.073 & 0.070 & 0.562 & 0.032 & 0.045 & & 0.330 & & 0.33 & 0 & 0.330 \\
\hline 1998 & -0.053 & 0.063 & 0.136 & 0.619 & 0.020 & 0.053 & & 0.330 & & 0.33 & 0 & 0.330 \\
\hline 1999 & 0.149 & 0.066 & 0.005 & 0.619 & 0.094 & 0.046 & & 0.330 & & 0.33 & 0 & 0.330 \\
\hline 2000 & -0.110 & 0.069 & 0.111 & 0.619 & -0.025 & 0.054 & & 0.330 & & 0.33 & 0 & 0.330 \\
\hline 2001 & 0.148 & 0.062 & 0.049 & 0.619 & 0.110 & 0.044 & & 0.330 & & 0.33 & 0 & 0.330 \\
\hline 2002 & 0.022 & 0.064 & 0.084 & 0.619 & 0.046 & 0.049 & & 0.330 & & 0.33 & 0 & 0.330 \\
\hline 2003 & 0.241 & 0.056 & -0.009 & 0.488 & 0.159 & 0.051 & & 0.330 & & 0.33 & 0 & 0.330 \\
\hline 2004 & 0.253 & 0.061 & 0.062 & 0.488 & 0.190 & 0.058 & & 0.330 & & 0.33 & 0 & 0.330 \\
\hline 2005 & 0.067 & 0.061 & 0.082 & 0.488 & 0.072 & 0.054 & & 0.330 & & 0.33 & 0 & 0.330 \\
\hline
\end{tabular}




\section{Bibliography}

Baillie, R. T. and DeGennaro, R. P. (1990). Stock Returns and Volatility. Journal of Financial and Quantitative Analysis, 25(2):203-214.

Bernstein, W. J. and Arnott, R. D. (2003). Earnings Growth: The Two Percent Dilution. Financial Analysts Journal, 59(5):47-55.

Blume, M. E. (1974). Unbiased Estimators of Long-Run Expected Rates of Return. Journal of the American Statistical Association, 69(347):634-638.

Booth, L. (1999). Estimating the equity risk premium and equity costs: New ways of looking at old data. Journal of Applied Corporate Finance, 12(1):100-112.

Booth, L. (2001). Equity Market Risk Premiums in the US and Canada. working paper, CIT Chair in Structured Finance, Rotman School of Management.

Boudoukh, J., Richardson, M., and Whitelaw, R. F. (1997). Nonlinearities in the Relation between the Equity Risk Premium and the Term Structure. Management Science, 43(3):371-385.

Boyle, G. (2005). Risk, Expected Return, and the Cost of Equity Capital. working paper, NZ Institute for the Study of Competition and Regulation.

Brennan, M. (1970). Taxes, market valuation and corporate financial policy. National Tax Journal, 25:417-427. 
Brigham, E. F. (1966). An Analysis of Convertible Debentures: Theory and Some Empirical Evidence. Journal of Finance, 21(1):35-54.

Brown, S., Goetzmann, W., and Ross, S. (1995). Survival. Journal of Finance, 50:853-873.

Campbell, J. Y. (1987). Stock Returns and the Term Structure. Journal of Financial Economics, 18:373-399.

Chay, J., Marsden, A., and Stubbs, R. (1993). Historical Rates of Return to Equities, Bonds, and the Equity Risk Premium: New Zealand Evidence. Pacific Accounting Review, 5(1):27-46.

Chay, J., Marsden, A., and Stubbs, R. (1995). Investment returns in the New Zealand market: 1931-1994. New Zealand Investment Analyst, 16:19-27.

Claus, J. and Thomas, J. (2001). Equity Premia as Low as Three Percent? Evidence from Analysts' Earnings Forecasts for Domestic and International Stock Markets. Journal of Finance, LVI(5).

Cliffe, C. and Marsden, A. (1992). The effect of dividend imputation on company financing decisions and the cost of capital in New Zealand. Pacific Accounting Review, 4:1-30.

Conrad, J. and Kaul, G. (1988). Time-Variation in Expected Returns. Journal of Business, 61(4):409-425.

Cooper, I. (1996). Arithmetic versus Geometric Mean Estimators: Setting Discount Rates for Capital Budgeting. European Financial Management, 2(2):157-167.

Cornell, B. (1999). The Equity Risk Premium: The Long-run Future of the Stock Market. John Wiley and Sons, New York.

Credit Suisse First Boston (1998). Equity Valuation Methodology. 
Damodaran, A. (1999). Estimating Equity Risk Premiums. working paper, Stern School of Business.

Dimson, E., Marsh, P., and Staunton, M. (2000). Risk and Return in the 20th and 21st Centuries. Business Strategy Review, 11(2):1-18.

Evans, M. D. D. (1994). Expected Returns, Time-Varying Risk, and Risk Premia. Journal of Finance, 49(2):655-679.

Fama, E. F. and French, K. R. (1989). Business Conditions and Expected Returns on Stocks and Bonds. Journal of Financial Economics, 25:23-49.

Fama, E. F. and French, K. R. (1999). The corporate cost of capital and the return on corporate investment. The Journal of Finance, 54(6):1939-67.

Ferson, W. E. and Harvey, C. R. (1991). The Variation of Economic Risk Premiums. Journal of Political Economy, 99(2):385-415.

French, K. R., Schwert, W. G., and Stambaugh, R. F. (1987). Expected Stock Returns and Volatility. Journal of Financial Economics, 19:3-29.

Glosten, L. R., Jagannathan, R., and Runkle, D. E. (1993). On the Relation between the Expected Value and the Volatility of the Nominal Excess Return on Stocks. Journal of Finance, 48(5):1779-1801.

Gordon, M. J. (1962). The Investment, Financing and Valuation of the Corporation. Irwin, Homewood.

Goyal, A. and Santa-Clara, P. (2003). Idiosyncratic Risk Matters! Journal of Finance, 58(3):975-1007.

Harris, R. S. and Marston, F. C. (1992). Estimating Shareholder Risk Premia Using Analysts' Growth Forecasts. Financial Management, 21(2):63-70.

Harvey, C. R. (1989). Time-Varying Conditional Covariances in Tests of Asset Pricing Models. Journal of Financial Economics, 24:289-317. 
Hirschey, M. (1985). Market structure and market value. The Journal of Business, 58(1):89-98.

Ibbotson, R. G. and Sinquefield, R. A. (1976). Stocks, Bonds, Bills, and Inflation: Year-by-Year Historical Returns (1926-1974). Journal of Business, 49(1):11-47.

Indro, D. C. and Lee, W. Y. (1997). Biases in Arithmetic and Geometric Averages as Estimates of Long-Run Expected Returns and Risk Premia. Financial Management, 26(4):81-90.

Jorion, P. and Goetzmann, W. N. (1999). Global Stock Markets in the Twentieth Centur. Journal of Finance, 54(3):953-980.

Kandel, S. and Stambaugh, R. (1987). On Correlation and Inferences about Mean-Variance Efficiency. Journal of Financial Economics, 18:61-90.

Lally, M. (1992). The CAPM Under Dividend Imputation. Pacific Accounting Review, 35:63-72.

Lally, M. (2000). The Real Cost of Capital in New Zealand: Is it too high? New Zealand Business Roundtable.

Lally, M. (2001). Estimating the Market Risk Premium by ForwardLooking Methods. The New Zealand Investment Analyst, 22:28-30.

Lally, M. (2002). Time-varying Market Leverage, the Market Risk Premium and the Cost of Capital. Journal of Business Finance and Accounting, 29:1301-1318.

Lally, M. and Marsden, A. (2004a). Estimating the Market Risk Premium in New Zealand through the Siegel Methodology. Accounting Research Journal, 17(2):93-101.

Lally, M. and Marsden, A. (2004b). Tax-Adjusted Market Risk Premiums in New Zealand: 1931-2002. Pacific-Basin Finance Journal, 12(3):291-310. 
Lintner, J. (1965). The Valuation of Risky Assets and the Selection of Investments in Stock Portfolios and Capital Budgets. Review of Economics and Statistics, 47:13-37.

Marsden, A. (2005). Historical and Siegel Estimates of the Market Risk Premium in New Zealand. ISCR presentation on The Regulatory Cost of Capital II: What is the Market Risk Premium?

Mayfield, E. S. (2004). Estimating the Market Risk Premium. Journal of Financial Economics, 73:465-496.

McCulloch, B. and Leonova, D. (2005). The Market Equity Risk Premium. Treasury paper, New Zealand Treasury.

Merton (1980). On Estimating the Expected Return on the Market. Journal of Financial Economics, 8:323-361.

Miles, J. A. and Ezzell, J. R. (1985). Reformulating Tax Shield Valuation: Note. Journal of Finance, pages 1485-1492.

Miller, M. H. (1977). Debt and Taxes. Journal of Finance, 32(2):261-275.

Modigliani, F. and Miller, M. H. (1958). The Cost of Capital, Corporation Finance and the Theory of Investment. American Economic Review, 48(3):261-297.

Modigliani, F. and Miller, M. H. (1963). Corporate Income Taxes and the Cost of Capital: A Correction. American Economic Review, 53(3):433-443.

Mossin, J. (1966). Equilibrium in a Capital Asset Market. Econometrica, 24:768-783.

Pastor, L. and Stambaugh, R. F. (2001). The Equity Premium and Structural Breaks. Journal of Finance, 56(4):1207-1239.

PricewaterhouseCoopers (2002). The New Zealand Equity Market Risk Premium. 
Roll, R. (1977). A Critique of the Asset Pricing Theory's Tests; Part I: On Past and Potential Testability of the Theory. Journal of Financial Economics, 4:129-176.

Roll, R. and Ross, S. (1994). On the Cross-Sectional Relation Between Expected Returns and Betas. Journal of Finance, 49:101-121.

Schroeder, D. (2005). The Implied Equity Risk Premium-An Evaluation of Empirical Methods. Bonn Econ Discussion Papers 13, Bonn Graduate School of Economics, University of Bonn.

Scruggs, J. T. (1998). Resolving the Puzzling Intertemporal Relation between the Market Risk Premium and Conditional Market Variance: A Two-Factor Approach. Journal of Finance, 53(2):575-603.

Shanken, J. (1987). Multivariate Proxies and Asset Pricing Relations: Living with the Roll Critique. Journal of Financial Economics, 18:91-110.

Sharpe, W. (1964). Capital Asset Prices: A Theory of Market Equilibrium under Conditions of Risk. Journal of Finance, 19:425-442.

Siegel, J. J. (1992). The Equity Premium: Stock and Bond Returns Since 1802. Financial Analysts Journal, (Jan-Feb):28-38.

Siegel, J. J. (1999). The Shrinking Equity Premium. Journal of Portfolio Management, pages 10-17.

Siegel, J. J. (2005). Perspectives on the Equity Risk Premium. Financial Analysts Journal, pages 61-73.

Turner, C. M., Startz, R., and Nelson, C. R. (1989). A Markov Model of Heteroskedasticity, Risk, and Learning in the Stock Market. NBER Working Paper Series 2818, National Bureau of Economic Research. 